\title{
A new modal-based approach for modelling the bump foil structure in the simultaneous solution of foil-air bearing rotor dynamic problems
}

DOI:

10.1016/j.jsv.2017.02.028

\section{Document Version}

Accepted author manuscript

Link to publication record in Manchester Research Explorer

Citation for published version (APA):

Hassan, M. F. B., \& Bonello, P. (2017). A new modal-based approach for modelling the bump foil structure in the simultaneous solution of foil-air bearing rotor dynamic problems. Journal of Sound and Vibration. https://doi.org/10.1016/j.jsv.2017.02.028

\section{Published in:}

Journal of Sound and Vibration

\section{Citing this paper}

Please note that where the full-text provided on Manchester Research Explorer is the Author Accepted Manuscript or Proof version this may differ from the final Published version. If citing, it is advised that you check and use the publisher's definitive version.

\section{General rights}

Copyright and moral rights for the publications made accessible in the Research Explorer are retained by the authors and/or other copyright owners and it is a condition of accessing publications that users recognise and abide by the legal requirements associated with these rights.

\section{Takedown policy}

If you believe that this document breaches copyright please refer to the University of Manchester's Takedown Procedures [http://man.ac.uk/04Y6Bo] or contact uml.scholarlycommunications@manchester.ac.uk providing relevant details, so we can investigate your claim.

\section{OPEN ACCESS}




\title{
A New Modal-Based Approach for Modelling the Bump Foil Structure in the Simultaneous Solution of Foil-Air Bearing Rotor Dynamic Problems
}

\author{
M F Bin Hassan, P Bonello ${ }^{1}$
}

School of Mechanical, Aerospace and Civil Engineering, University of Manchester, UK

\begin{abstract}
Recently-proposed techniques for the simultaneous solution of foil-air bearing (FAB) rotor dynamic problems have been limited to a simple bump foil model in which the individual bumps were modelled as independent spring-damper (ISD) subsystems. The present paper addresses this limitation by introducing a modal model of the bump foil structure into the simultaneous solution scheme. The dynamics of the corrugated bump foil structure are first studied using the finite element (FE) technique. This study is experimentally validated using a purpose-made corrugated foil structure. Based on the findings of this study, it is proposed that the dynamics of the full foil structure, including bump interaction and foil inertia, can be represented by a modal model comprising a limited number of modes. This full foil structure modal model (FFSMM) is then adapted into the rotordynamic FAB problem solution scheme, instead of the ISD model. Preliminary results using the FFSMM under static and unbalance excitation conditions are proven to be reliable by comparison against the corresponding ISD foil model results and by crosscorrelating different methods for computing the deflection of the full foil structure. The rotorbearing model is also validated against experimental and theoretical results in the literature.
\end{abstract}

Keywords: Foil-air bearings; modal analysis; nonlinear vibration; tribology; rotordynamics 


\section{Nomenclature}

\begin{tabular}{|c|c|}
\hline()$^{\prime}$ & differentiation with respect to $\tau$ \\
\hline$B$ & foil width (along $Z_{\mathrm{f}}$-axis) \\
\hline$c$ & undeformed radial clearance of FAB \\
\hline D & diagonal damping matrix (eq. (10)) \\
\hline E & Young's Modulus \\
\hline$f_{\text {res }}$ & fundamental resonance of single isolated bump in $\mathrm{Hz}$ \\
\hline $\mathbf{f}_{\mathbf{p}}$ & vector of air pressure forces on bumps \\
\hline$F_{x}, F_{y}$ & Cartesian FAB forces \\
\hline$i, j$ & generic degrees of freedom \\
\hline$\tilde{h}$ & air film gap divided by $c$ \\
\hline $\mathbf{H}_{\mathbf{x}_{\mathrm{f}}}$ & foil modal matrix whose columns are $\boldsymbol{\phi}_{\mathbf{x}_{\mathrm{f}}}^{(r)}, r=1 \ldots n_{\mathrm{f}}$ \\
\hline $\mathbf{H}_{\mathbf{y}_{\mathrm{f}}}$ & foil modal matrix whose columns are $\boldsymbol{\phi}_{\mathbf{y}_{\mathrm{f}}}^{(r)}, r=1 \ldots n_{\mathrm{f}}$ \\
\hline$k_{\text {bump }}$ & stiffness of single independent bump \\
\hline $\mathbf{K}$ & FE stiffness matrix of foil structure \\
\hline$l_{\mathrm{b}}$ & length of one bump along $x_{\mathrm{f}}$-axis (Figure 2 ) \\
\hline$L$ & axial length of FAB \\
\hline$m_{r}$ & half-mass of rotor \\
\hline $\mathbf{M}$ & FE mass matrix of foil structure \\
\hline$n_{\text {bumps }}$ & number of bumps \\
\hline$n_{\mathrm{f}}$ & number of foil structure modes considered \\
\hline$n_{\text {state }}$ & total number of state variables in eq. (1) \\
\hline$N_{z}, N_{\theta}$ & number of points of FD grid along $\xi, \theta$ directions \\
\hline$p(\xi, \theta, \tau)$ & absolute air pressure at $(\xi, \theta)$ for FAB \\
\hline
\end{tabular}




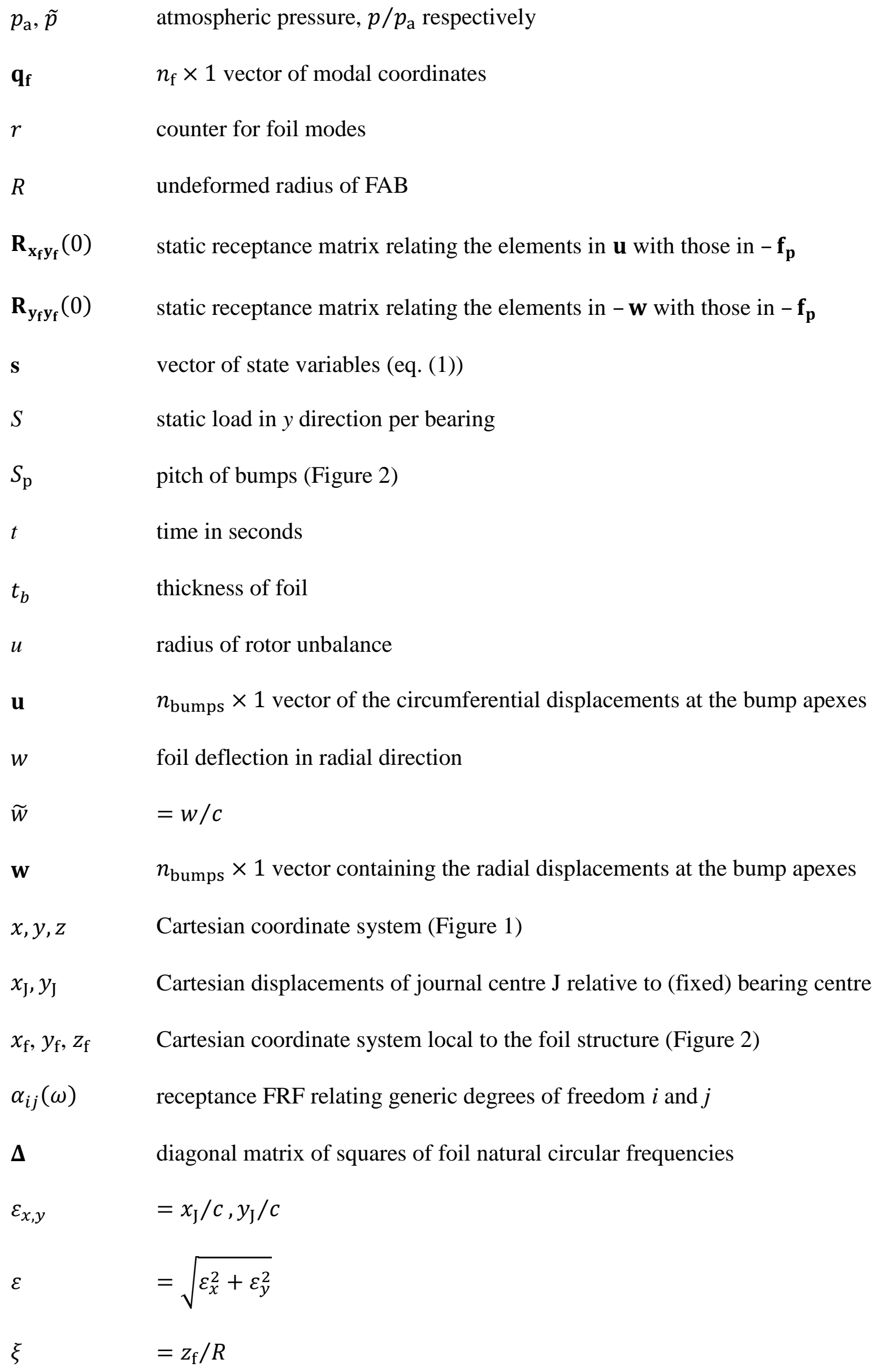




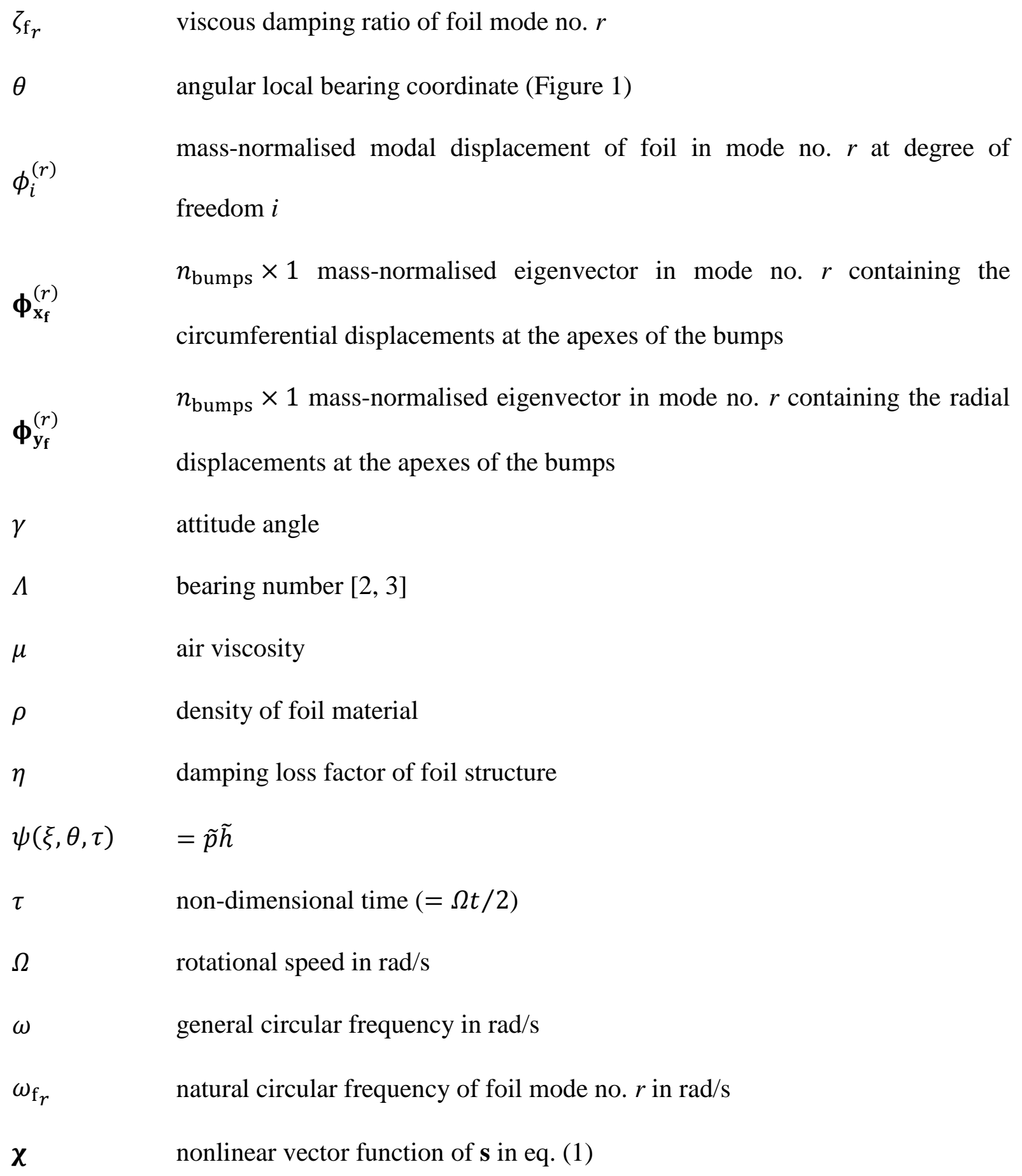




\section{INTRODUCTION}

A FAB (Figure 1(a)) supports the shaft by means of a cushion of air bounded by a flexible foil structure. The introduction of the foil structure resolves the problems associated with the very tight radial clearance required by a plain air bearing. With a $F A B$, the hydrodynamic air film pressure generated as the shaft turns pushes the foil boundary away, allowing the shaft to become completely airborne [1]. The dynamics of FAB turbomachinery are governed by the interaction between the rotor, air films and the foil structures, and exhibit nonlinear effects. The governing system of equations comprises the state (i.e. time-based first order differential) equations of the air films, foils and rotor and can be expressed in state-space form as $[2,3]$ :

$$
\mathbf{s}^{\prime}=\chi(\tau, \mathbf{s})
$$

where ( )' denotes differentiation with respect to the time variable $\tau, \mathbf{s}$ is the state vector, containing the $n_{\text {state }}$ state variables (respectively relating to the air film, foil and rotor domains) and $\chi$ is a vector of nonlinear functions of the state variables.

Prior to the work by the co-author [2,3], the simultaneous solution of the state equations in (1) was avoided due to the computational burden involved. As explained in $[2,3]$, this was typically done by approximating the subset of state equations relating to the air film as algebraic equations, effectively decoupling them from the rest of the equations. A non-simultaneous ("time-lagging") solution scheme was applied wherein the current value of the local air film thickness, and its rate of change with time, were estimated based on the foil and rotor displacements at the previous time step (e.g. as used in [4]). The work in [2, 3] has shown that an efficient simultaneous solution is possible in both the time and frequency domains, which preserves the state-space format of eq. (1) (and thus the true simultaneous coupling of its components), alleviating the potential convergence issues suffered by decoupled integration schemes [5]. 
The basic strategy for the simultaneous time-domain solution introduced in [2] has been independently verified by other researchers in [6] and successfully used to correlate with experimental results in [7], [5] and [3]. However, the simultaneous solution schemes in [2-3, 5-7] are based on a simplified spring-damper model of the foil structure (as described below). The present paper addresses this simplification by devising a means of including more advanced features of the foil (namely, bump interaction and inertia) into the simultaneous solution scheme. The foil structure considered will be of the "first generation" type shown in Figure 1(a), consisting of a single corrugated strip (comprising a series of bumps) underneath a top foil covering.

In most previous work, the individual bumps were modelled as independent spring-damper (ISD) subsystems. The analytical bump stiffness introduced by Walowit and Anno [8], and used by others e.g. [9], modelled the bump as a straight beam with simply supported ends. More sophisticated individual bump stiffness expressions, based on beam theory, but including the effects of curvature (Castigliano's Theorem), the fixing of the weld (in the case of the first bump), and the lateral friction forces at the ends, were introduced in $[10,11]$. With regard to the issue of damping, which is mainly the result of the Coulomb friction between the foil and bearing shell, an equivalent linear viscous damping coefficient has been used in FAB calculations e.g. [1-3, 5-7, 12]. This was either extracted from an analytical model of a single bump [10] or from a full numerical (FE) and/or experimental study of the full corrugated structure e.g. [13, 7].

As an improvement to the ISD, models that take into account of bump interaction have been proposed, most notably that of Le Lez et al. [4]. The modelling in [4] used analytical methods (based on Castigliano's Theorem) to derive the terms in the stiffness matrix relating both transverse (radial) and longitudinal (circumferential) forces with the corresponding displacements. The model has been shown in $[4,14]$ to be useful for including actual Coulomb friction forces (rather than substituting them as equivalent damping). Inertia effects were not included in $[4,14]$ since it was reasoned that most applications will run far from the lowest resonance of the structure [14]. However, the resonance computed by Le Lez et al. in [14] $(9.2 \mathrm{kHz})$ was based on a single 
independent bump, rather than the whole foil structure. In the present paper, it will be shown that the fundamental frequency of a corrugated structure with 26 bumps similar to that in [4] is typically almost five times less $(1.9 \mathrm{kHz})$. Another work has incorporated an FE model of the bump foil structure, including its inertia, into the rotor-bearing problem [15], but ignored bump curvature, and is computationally cumbersome for simultaneous solution of the rotor-air-foil domains since it does not involve any modal reduction. In many works e.g. [1-15] the stiffness and inertia of the top foil are neglected and the present paper follows this approach. The work in [16] included the stiffness of the top foil but no significant improvement in correlation with experiment was reported.

The novelty of the present paper is the introduction of a modal model of the bump foil structure, based on FE analysis, into the rotor-bearing model, thus advancing the simultaneous solution scheme. The bump foil's physical degrees of freedom will be transformed into modal space using its undamped mode shapes. Since the number of effective modes is much less than the number of physical degrees of freedom, the model is computationally efficient while retaining key aspects of the FE model (bump interaction, inertia) that are not present in the ISD model. Section 2 presents a much-needed study of the free vibration mode shapes, frequency response functions, and modal superposition, for a corrugated foil structure. The study is then validated experimentally on a purpose-made bump foil in section 3, which also presents the manufacturing procedure. In section 4, the outcomes of the study in section 2 are adapted into the simultaneous solution of the nonlinear dynamic response of the FAB-rotor system shown in Figure 1(b). Although Coulomb friction is outside the scope of the present paper, section 4.1 includes a note on the method's adaptability to this type of friction that is relevant to FABs. The results of the FAB-rotor analysis are presented and discussed in section 5. In section 6, the rotor-bearing model is validated against published results. The preliminary research of this paper appears in the authors' conference paper [17], which does not include the material in sections 3 and 6. The present journal paper also contains additional verification test results in sections 2 and 5 and additional details throughout. 


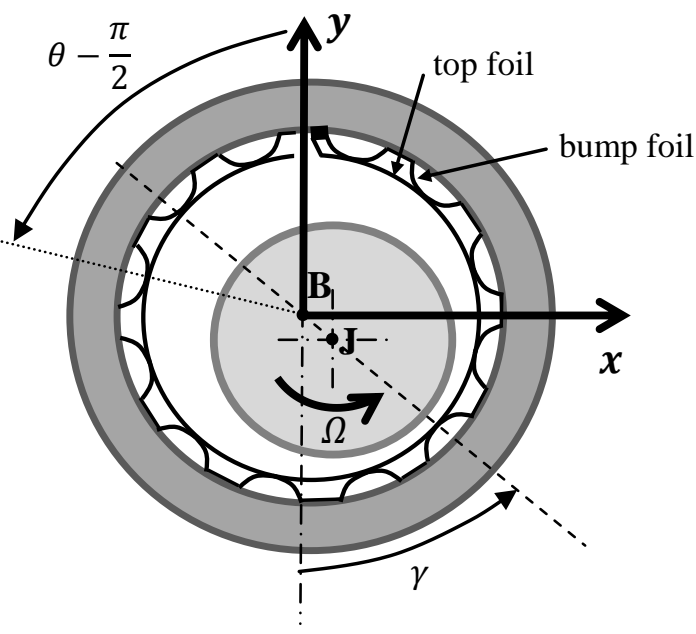

(a)

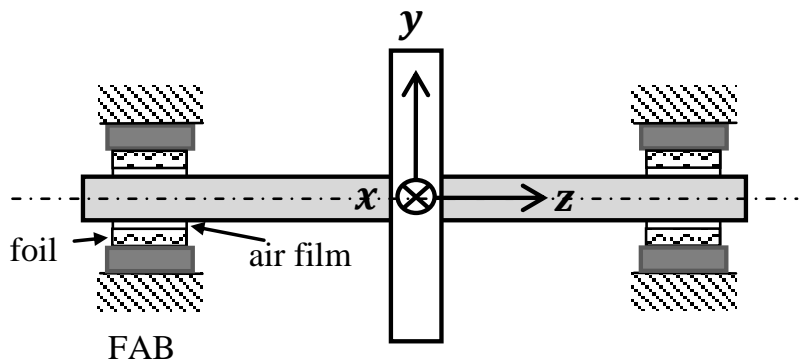

(b)

Figure 1: FAB (a) and symmetric rigid rotor-FAB system (b)

\section{FINITE ELEMENT (FE) DYNAMIC ANALYSIS OF BUMP FOIL}

The focus of this section is the FE dynamic analysis of the full corrugated bump foil structure (Figure 2), whose left-hand edge is fully constrained (welded) and right-hand edge constrained only in the $y_{\mathrm{f}}$ and $z_{\mathrm{f}}$ directions (i.e. simply supported). It is noted that, in Figure 2, the Cartesian axes $\left(x_{\mathrm{f}}, y_{\mathrm{f}}, z_{\mathrm{f}}\right)$ are local to the foil, as distinct from the global rotor-bearing system axes $(x, y, z)$ in Figure 1. The structure in Figure 2 has the same geometry as that in $[4,14]$. It is noted that the width $B$ of the bump (along $z_{\mathrm{f}}$ axis) is equal to the bearing length $L$. Also, in Figure 2 , the $x_{\mathrm{f}}-z_{\mathrm{f}}$ plane, which corresponds to the bearing housing surface, is taken to be a flat plane (i.e. the curvature of the bearing shell is neglected). This assumption (which is tested in sub-section 2.1) was also made in $[4,14]$ and is reasonable because the ratio between the height of the bump strip layer 
to the radius of the bearing is very small. Hence, the longitudinal $\left(x_{\mathrm{f}}\right)$ direction corresponds to the circumferential direction of the bearing and the transverse $\left(y_{\mathrm{f}}\right)$ direction corresponds to the radial direction of the bearing. As indicated in Figure 2, each flat part ("tab") of the foil is free to slide smoothly along the bearing shell (i.e. in the $x_{\mathrm{f}}$ direction) but is assumed to stay in contact with it at all times by constraints in the radial $\left(y_{\mathrm{f}}\right)$ direction applied at nodes located along three lines oriented in the axial $\left(z_{\mathrm{f}}\right)$ direction (which appear as three sliding pivots in the $x_{\mathrm{f}}-y_{\mathrm{f}}$ plane view of Figure 2). Therefore, the system considered is an undamped linear structure, and therefore its FE analysis is a standard exercise that follows conventional discretisation techniques [18], used by commercial FE packages [19]. Despite this, to the authors' knowledge, the mode shapes of such a system have not been studied. It is also noted that this linear system is similar to that considered by Le Lez et al. [4], except that they did not consider its inertia and derived its static stiffness matrix. It is important to note that, if nonlinear (Coulomb) friction forces are considered, the nonlinear constraints they introduce must not be considered at this FE stage, since these nonlinear forces would then be added as external forces applied to the linear structure (that was pre-analysed by FE) when solving the full rotor-bearing problem, as done by Le Lez at al. [4]. Hence, the modal transformation based on the undamped linear system of this section will be applicable to that situation as well (see section 4.1).

The FE analysis is performed using ANSYS Mechanical [19]. The analysis is performed using two alternative ways: (a) analysis in two dimensions (2D) using beam elements in the $x_{\mathrm{f}}-y_{\mathrm{f}}$ plane and (b) analysis in three dimensions (3D) using solid elements. In either case, all nodes are constrained in the axial $\left(z_{\mathrm{f}}\right)$ direction. The 3D-FE analysis allows the variation of deflection with axial position. The beam element used in the 2D-FE is BEAM188 which is a linear (2-node) beam element in 3-D space (i.e. has six degrees of freedom at each node) [19]. The solid element used in the 3D-FE is SOLID186, which has 20-nodes [19]. A Poisson ratio of 0.3 was used in the 3D-FE analysis. In either case, the system is analyzed for free vibration (modal analysis) and forced vibration 
(harmonic response). In the latter case, frequency response functions (FRFs) relating the displacement response at a degree of freedom with the excitation at the location and direction of another degree of freedom (i.e. receptance) are computed using two alternative methods: (i) full harmonic response analysis and (ii) modal superposition.

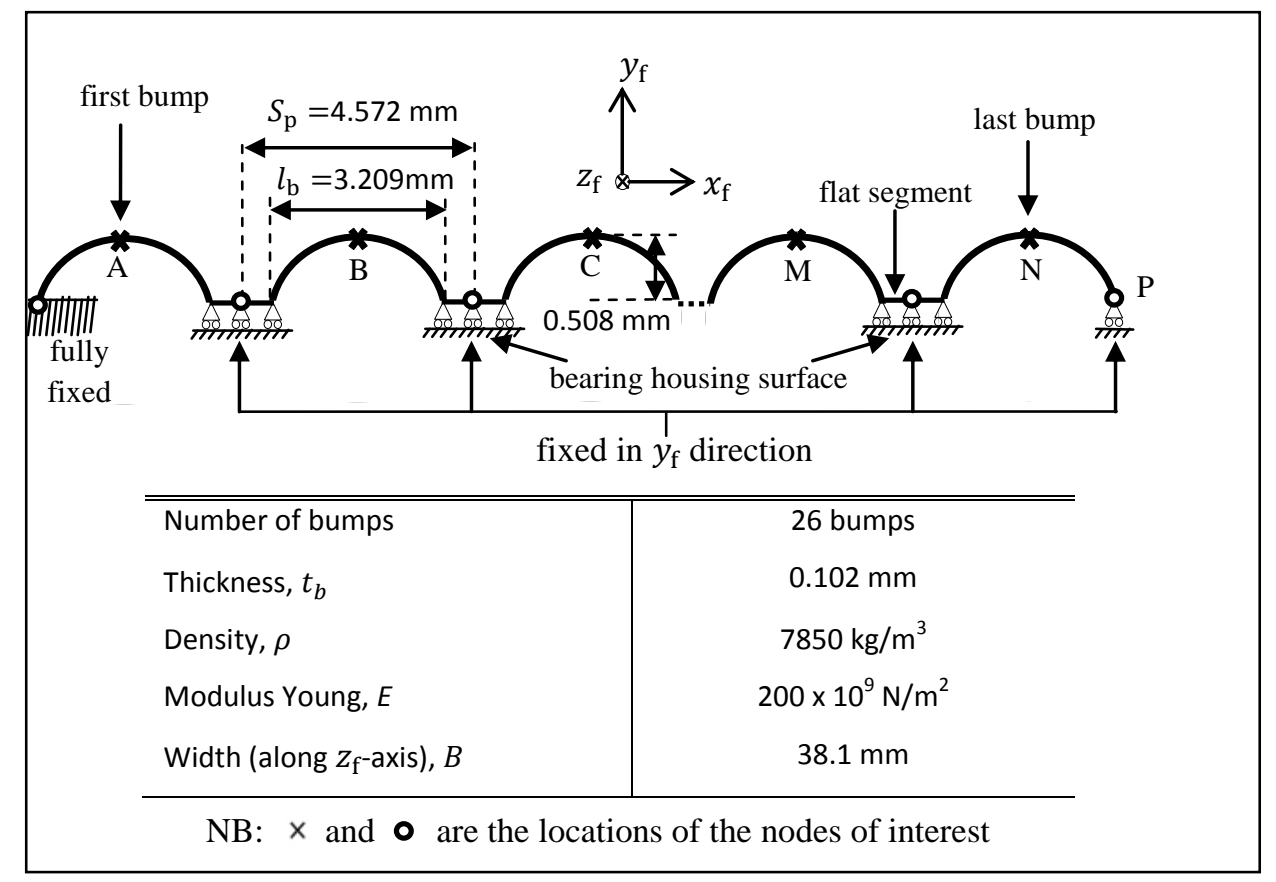

Figure 2: Bump foil dimensions and properties

As a preliminary analysis, a single independent bump that was pivoted at one end and free to slide in the $x_{\mathrm{f}}$-direction at the other end was considered. Its lowest natural frequency was found to be $18.67 \mathrm{kHz}$ by 2D FE analysis and $19.1 \mathrm{kHz}$ by 3D FE, both values being reasonably close with the value of $19.97 \mathrm{kHz}$ obtained analytically by assuming the bump to be a straight beam of length equal to the bump's arc-length $(3.42 \mathrm{~mm})$. The static stiffness in the radial $\left(y_{\mathrm{f}}\right)$ direction at the apex was found to be $0.94 \mathrm{MN} / \mathrm{m}$ by $2 \mathrm{D}-\mathrm{FE}$, which compares well with the analytical stiffness of 0.96 MN/m calculated using Castigliano's Theorem by modelling the bump as a curved beam. These values for the single independent bump stiffness $k_{\text {bump }}$ agree with the value of $1 \mathrm{MN} / \mathrm{m}$ quoted in [14]. It is noted that, in [14], the quoted foil fundamental resonance of $9.2 \mathrm{kHz}$ was calculated using the approximate formula $f_{\text {res }} \approx\left(\sqrt{k_{\text {bump }} / m}\right) /(2 \pi)$, where $m$ is an effective mass. If the 
inertia of the top foil is neglected, the value of $m=0.0522$ grams (i.e. half the mass of the bump's arc-length), and $f_{\text {res }} \approx 22 \mathrm{kHz}$, agreeing reasonably well with the preceding FE analysis results. The quoted value for $m$ in [14] was 0.3 grams, so it is surmised that some allowance for the top foil inertia must have been made (though not mentioned), yielding $f_{\text {res }} \approx 9.2 \mathrm{kHz}$. In the present paper, the inertia of the top foil is not considered.

Attention is now focused on the full corrugated bump structure in Figure 2, with constraints as described in the first paragraph of this section. Table 1 shows the first five natural frequencies from both $2 \mathrm{D}$ and $3 \mathrm{D}$ finite element modal analyses. It is seen that the first resonance frequency has been drastically reduced to around $1.9 \mathrm{kHz}$. The natural frequencies computed by 2D and 3D FE analyses are very close, with differences ranging between $1.48 \%$ and $0.1 \%$. The corresponding mode-shapes computed by both 2D and 3D FE are also in close agreement, as seen in Figure 3, which presents the first two mass-normalised modes of vibration (the first and second columns respectively showing the coupled transverse (radial) and longitudinal (circumferential) displacements). As in Figure 2, the crosses refer to the apex points and the circles refer to the midpoints of the flat segments between the bumps, and the fixed and free edges. The coupling between the radial and longitudinal deformations is illustrated in Figure 3 by using larger crosses and circles for one half of the vibration cycle. It is noted that, in all five modes calculated, the apex of the last bump (i.e. nearest the free end) has very little radial deflection (i.e. the last cross in each of the curves in the first column of Figure 3). The reason for this is that the corresponding longitudinal displacements at the ends of the last bump are almost (but not quite) equal (as can be seen from the last two circles in each of the curves in the second column of Figure 3).

It is noted that, in the case of the 3D FE mode shape results in Figure 3, the profile that is plotted is that contained in the $x_{\mathrm{f}}-y_{\mathrm{f}}$ plane at the mid-section of the bearing. However, the profile was found to be virtually the same at other sections. This uniformity of the vibration mode shapes along the $Z_{\mathrm{f}}$-direction and the agreement between the mode shapes computed by $2 \mathrm{D}$ and $3 \mathrm{D} \mathrm{FE}$ analysis 
makes the inclusion of the modal analysis of the foil into the nonlinear dynamic analysis of FAB relatively easy (since the air film force on the bump can be based on the average pressure in $z_{\mathrm{f}^{-}}$ direction, as discussed in section 4).

\section{Table 1: First five natural frequencies of foil structure computed by FE}

\begin{tabular}{cccccc} 
analysis type & \multicolumn{5}{c}{ natural frequencies in $\mathbf{H z}$} \\
2D (beam), 10200 elements & 1907.6 & 5679.8 & 9326.8 & 12778.5 & 15981.5 \\
3D (solid), 29190 elements & 1879.7 & 5634.9 & 9336.5 & 12876.4 & 16130.5 \\
\% difference & -1.48 & -0.80 & 0.10 & 0.76 & 0.92
\end{tabular}

The receptance FRFs for 2D FE were then obtained directly from ANSYS Mechanical [19] using the harmonic response analysis (FHRA) and modal superposition (MS) options. In the case of FHRA the process involved large matrix inversion at each frequency [20]:

$$
\left[\alpha_{i j}(\omega)\right]=\left\{\mathbf{K}-\omega^{2} \mathbf{M}\right\}^{-1}
$$

where $\alpha_{i j}(\omega)$ is the FRF relating generic degrees of freedom $i$ and $j$ and $\mathbf{K}$ and $\mathbf{M}$ the stiffness and mass matrices respectively. With 2D FE, these matrices were $20400 \times 20400$. In the case of MS, the FRFs were output more rapidly using the truncated modal series formula [20]:

$$
\alpha_{i j}(\omega)=\sum_{r=1}^{n_{\mathrm{f}}}\left\{\phi_{i}^{(r)} \phi_{j}^{(r)} /\left(\omega^{2}-\omega_{\mathrm{f}_{r}}^{2}\right)\right\}
$$

where $\omega_{\mathrm{f}_{r}}(\mathrm{rad} / \mathrm{s})$ is the natural frequency of mode no. $r, \phi_{i}^{(r)}, \phi_{j}^{(r)}$ are the elements of the corresponding mass-normalised eigenvectors evaluated at degrees of freedom $i$ and $j$ respectively, and $n_{\mathrm{f}}$ is the number of foil structure modes considered.

Using FHRA at zero frequency, the bump stiffness in the radial $\left(y_{\mathrm{f}}\right)$ direction was found to range from a maximum of $3.2 \mathrm{MN} / \mathrm{m}$ at the bump closest to the weld (see Figure 2), through to $2.8 \mathrm{MN} / \mathrm{m}$ 
at the middle bump and $1.8 \mathrm{MN} / \mathrm{m}$ at the bump nearest the free end (i.e. consistently higher than that of an independent bump with simply supported ends).
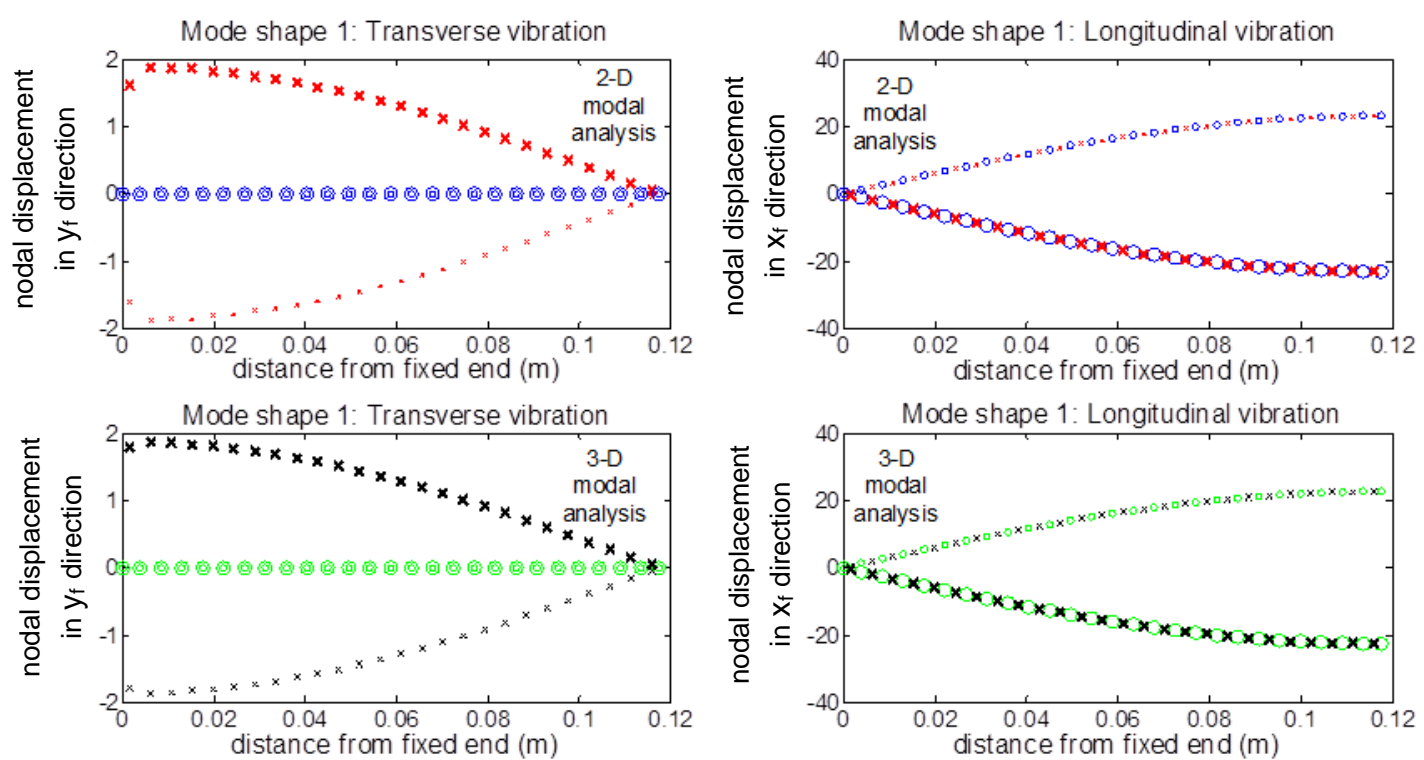

(a)
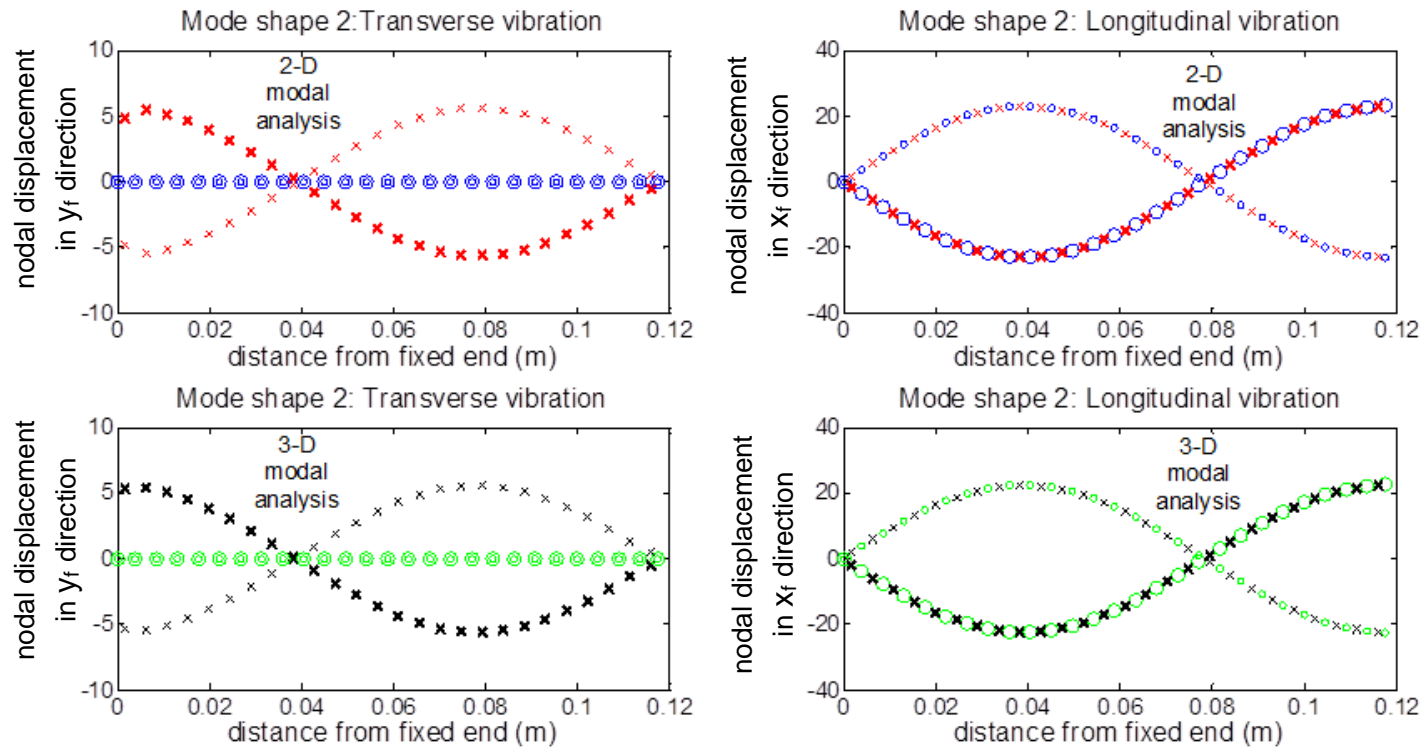

(b)

Figure 3: First two mode shapes of the bump foil structure: (a) first mode; (b) second mode (in each of (a) and (b), the first and second rows show the 2D FE, 3D FE results respectively; the crosses refer to the apex points and the circles refer to the other nodes of interest, as per Figure 2). 
Figure 4 compares the exact FRFs computed by the FHRA with those obtained by MS with $n_{\mathrm{f}}=5$. As can be seen from Figure 4(a), the MS method was not accurate in reproducing the FRF $\alpha_{i j}(\omega)$ when both degrees of freedom $i$ and $j$ were in the radial $\left(y_{\mathrm{f}}\right)$ direction. However, the MS method was quite accurate in reproducing $\alpha_{i j}(\omega)$ when at least one of the degrees of freedom was in the longitudinal $\left(x_{\mathrm{f}}\right)$ direction. Moreover, when the exact FRFs computed by the FHRA facility in ANSYS Mechanical [19] were fitted using the right hand side of the MS equation (3) with $n_{\mathrm{f}}=5$, following the multi-degree-of-freedom curve-fitting process (so-called 'lightly-damped' method [20]), all five eigenvectors extracted were in very close agreement with those computed by $2 \mathrm{D}$ or 3D FE (Figure 3) for both longitudinal and radial waveforms.

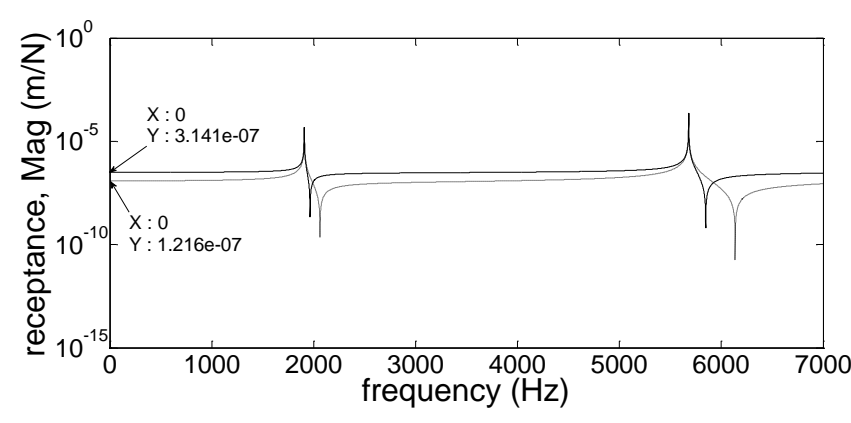

(a)

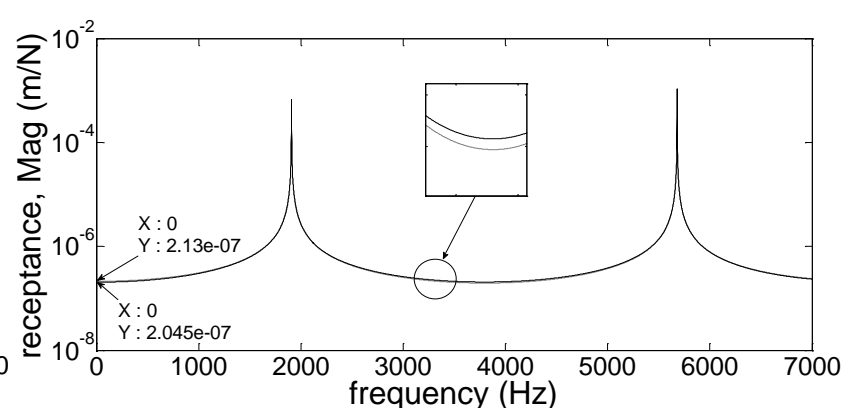

(b)

Figure 4: Receptance FRF of bump foil structure using FHRA ( - ) and MS with $n_{\mathrm{f}}=5(-----)$ for

(a) typical point FRF in radial direction and (b) typical transfer FRF relating longitudinal and radial degrees of freedom (FRF in (a) is $\alpha_{\mathrm{A}_{y_{\mathrm{f}}} \mathrm{A}_{y_{\mathrm{f}}}}(\omega)$, relating $y_{\mathrm{f}}$-displacement at A with $y_{\mathrm{f}}$-force at A, see Figure 2; FRF in (b) is $\alpha_{\mathrm{A}_{x_{\mathrm{f}}} \mathrm{A}_{y_{\mathrm{f}}}}(\omega)$, relating $x_{\mathrm{f}}$-displacement at A with $y_{\mathrm{f}}$-force at A).

\subsection{Effect of curvature of bearing sleeve}

Although the height of the bumps is much smaller than the radius of the bearing sleeve, it is worth investigating the assumption of neglecting the curvature of the bearing sleeve, in the absence of other research on the modal analysis of bump foil structures. Hence, the authors repeated the 2DFE analysis of the bump structure (i.e. using the beam elements), taking into account of the 
curvature of the bearing sleeve i.e. with the axes $x_{\mathrm{f}}$ and $y_{\mathrm{f}}$ truly representing local axes that are respectively tangential and radial with respect to the inner surface of the bearing shell. The same constraints as before were applied using the cylindrical coordinate system facility in ANSYS Mechanical [19]. It was found that the first five frequencies with a bearing radius of $19.05 \mathrm{~mm}$ were $2227.2,6620.2,10836.9,14780.4,18384.2 \mathrm{~Hz}$, which respectively represent increments of $16.75 \%, 16.56 \%, 16.19 \%, 15.67 \%, 15.03 \%$ over the frequencies in the first data row of Table 1 (which corresponds to an infinite bearing radius). As can be seen from Figures 5(a1,b1)-5(b5,b5), the mode shapes for the finite bearing radius case (first column) are virtually indistinguishable from the infinite bearing radius case (second column). The effect of the bearing curvature on the static stiffness of the first bump at its apex in the radial direction was to increase it by a modest $6.25 \%$.

The rotor-bearing simulations presented in Sections 5 and 6 use the foil modal parameters (natural frequencies and mode shapes) computed in this sub-section (i.e. accounting for bearing sleeve curvature). However, in view of the above observations, the rotor-bearing simulations presented in Sections 5 and 6 are in fact negligibly affected by the use of modal parameters computed from the case of infinite bearing sleeve radius instead of finite bearing sleeve radius (discrepancies between the two cases are only visible under considerable magnification). This justifies the assumption made by Le Lez et al. [4] i.e. neglecting bearing sleeve curvature for the size bearing used in this study. In any case, the principle of modal superposition to represent the radial and circumferential displacements remains unchanged and the method allows the analyst to use the mode shapes with bearing curvature in rotor-bearing calculations where this is deemed necessary. 

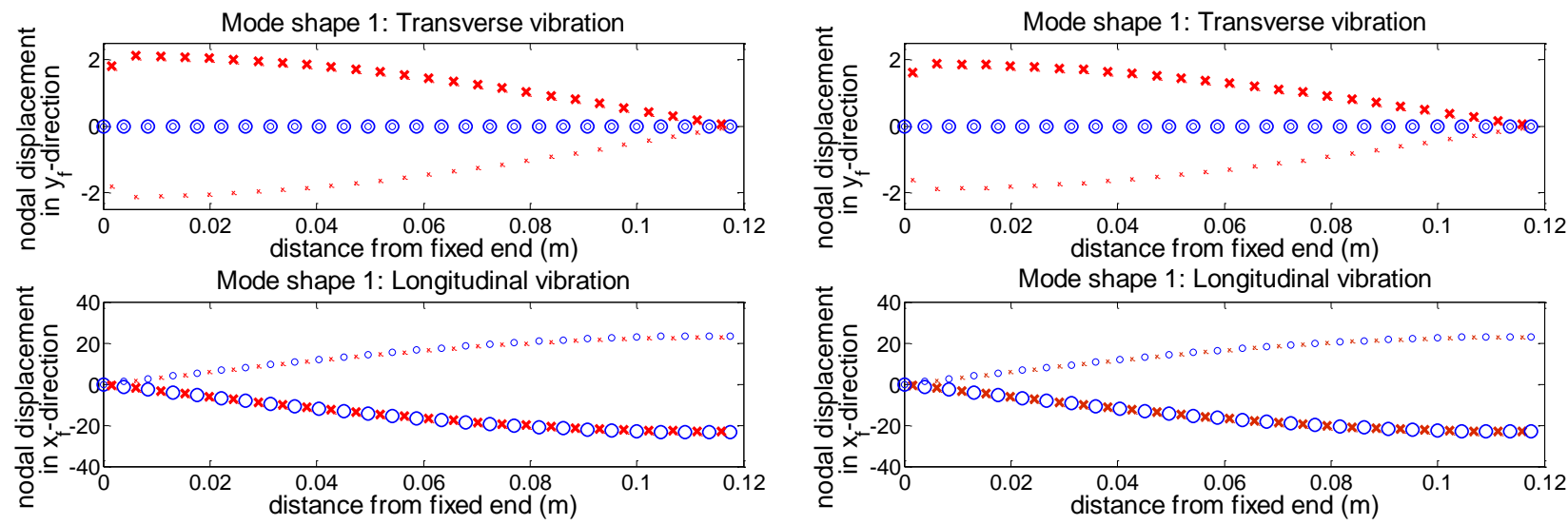

(a1)

(b1)
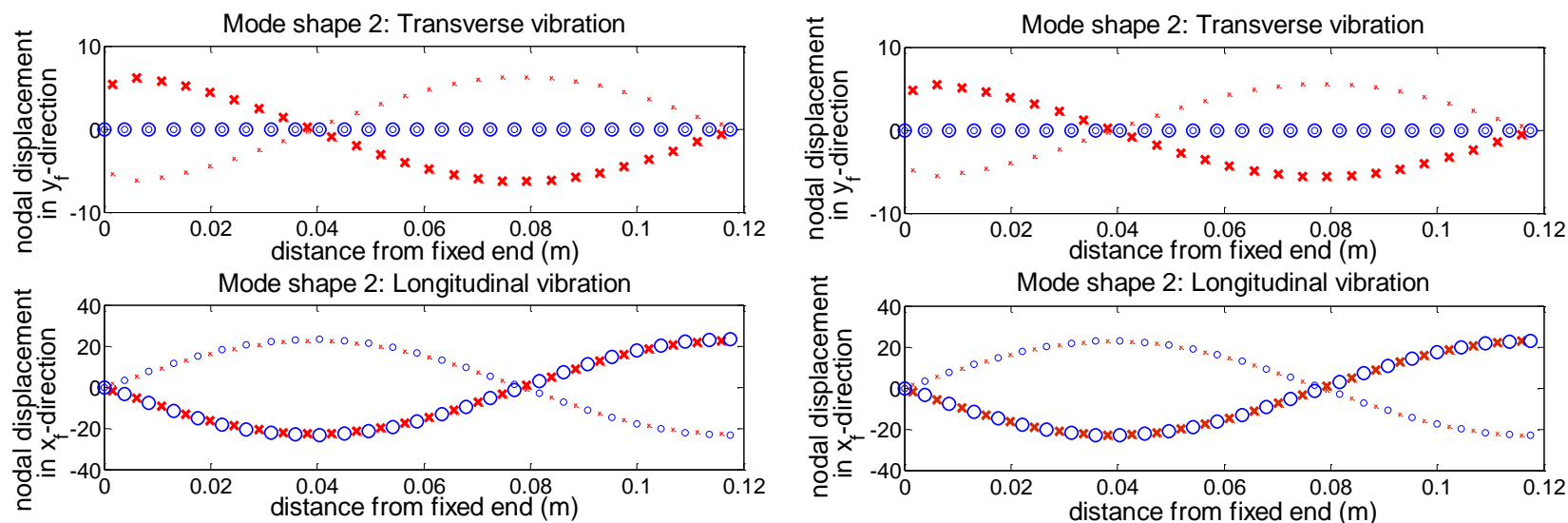

(a2)

(b2)
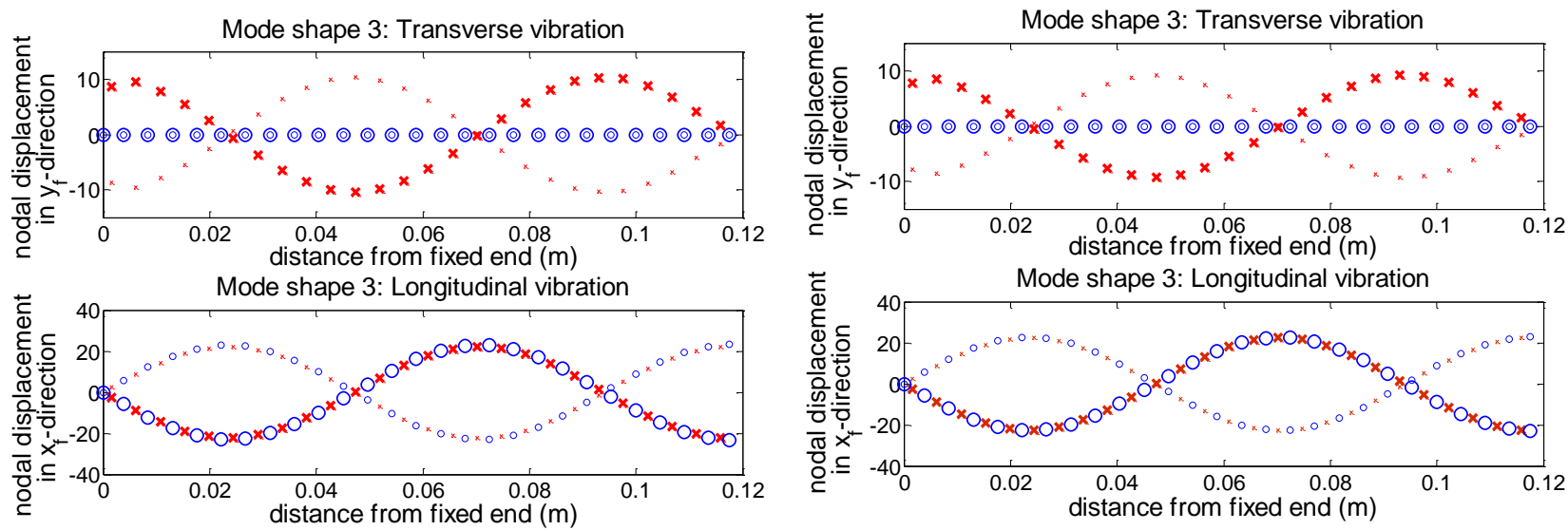

(a3)

(b3)

Figure 5: First five mode shapes of the bump foil structure, computed using 2D FE (beam elements): with bearing sleeve curvature considered (first column (a1)-(a5)); without bearing sleeve curvature (second column (b1)-(b5)) (the crosses refer to the apex points and the circles refer to the other nodes of interest, as per Figure 2). 


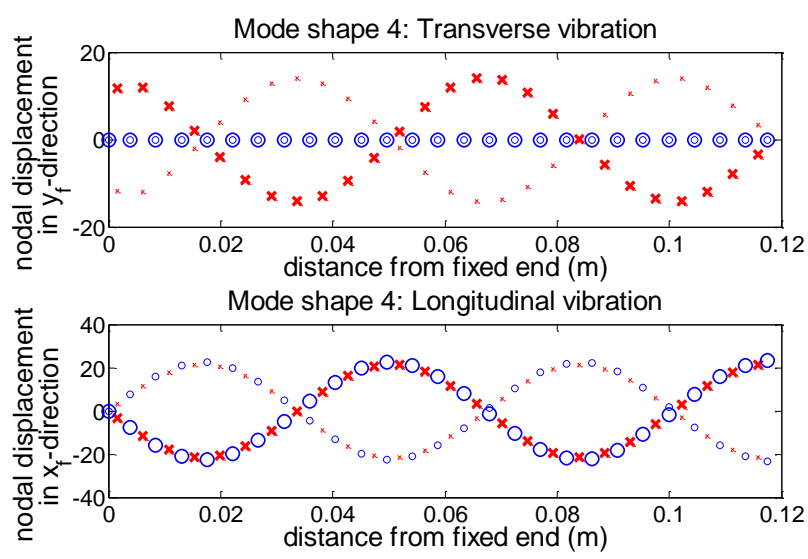

(a4)
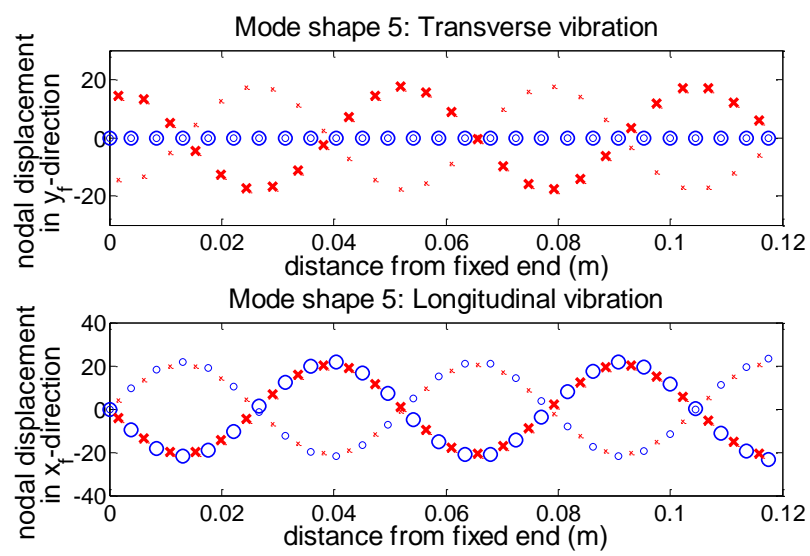

(a5)
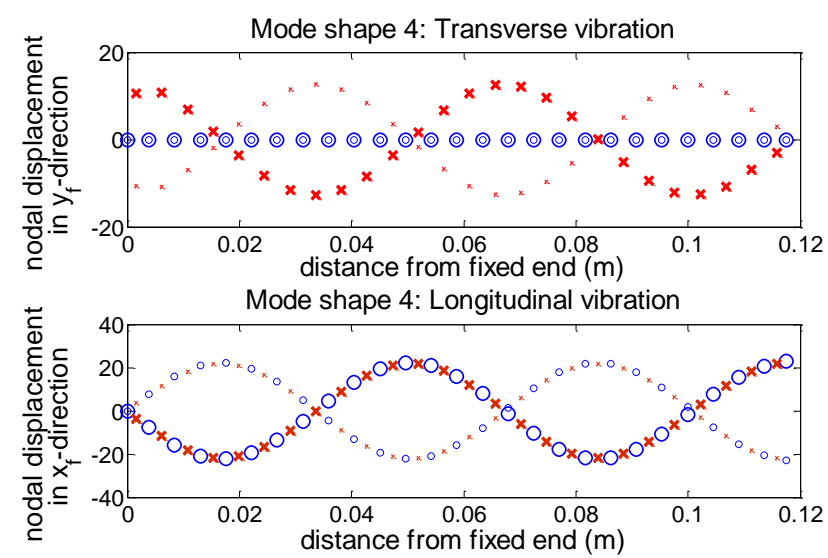

(b4)
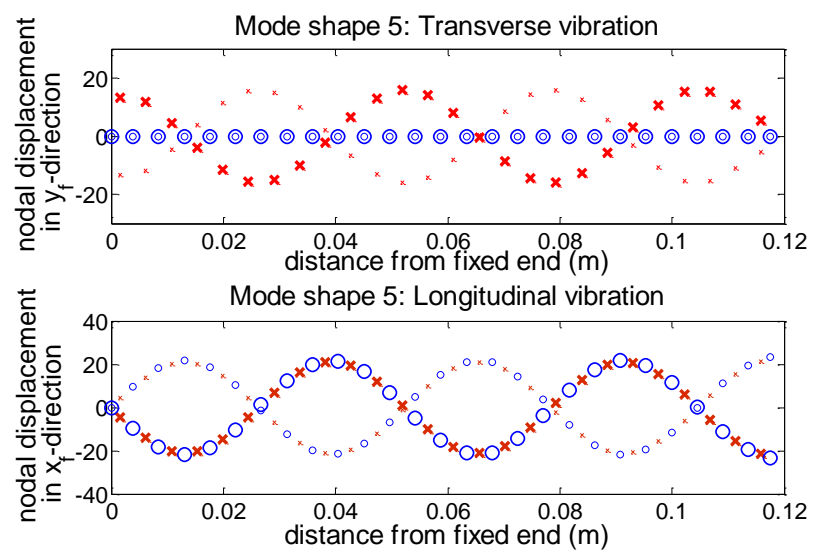

(b5)

Figure 5 (cont'd): First five mode shapes of the bump foil structure, computed using 2D FE (beam elements): with bearing sleeve curvature considered (first column (a1)-(a5)); without bearing sleeve curvature (second column (b1)-(b5)) (the crosses refer to the apex points and the circles refer to the other nodes of interest, as per Figure 2).

\section{EXPERIMENTAL VALIDATION OF BUMP FOIL MODEL}

Experimental validation of the above analysis of the full bump foil structure was obtained through impact tests on a custom-made bump foil structure. The forming tool used to make it was itself purpose-built at the University of Manchester according to the design originally introduced by NASA researchers [21] and subsequently used in [22]. With reference to Figure 6, the bump forming tool consisted of upper and lower bump forming dies contained in their respective die beds. 
The die beds were machined from mild steel using a conventional milling machine and surface grinder. The forming dies were made from SAE A-2 tool steel [22] and manufactured using a wire cut electrical discharge machine $(\mathrm{EDM})$ in order to obtain a surface finish of up to $0.05 \mu \mathrm{m}$ accuracy. The mating convex/concave profiles of the upper/lower dies respectively followed the bump foil geometry shown in Figure 2 with a tolerance of $\pm 0.001 \mathrm{~mm}$. A flat sheet of Inconel 718 , of $0.1 \mathrm{~mm}$ thickness and cut to a width of $38.1 \mathrm{~mm}$, was used to make the bump foil. This was formed by placing the flat sheet in between the lower and upper dies, which were then pressed onto each other with a force of $66.72 \mathrm{kN}$ [22] from an Instron 4507 machine, using the alignment pins for guidance. This resulted in a bump foil structure with 30 bumps, which was then cut to retain the required number of bumps (26). The subsequent heat treatment recommended in [21] was not deemed necessary since the foil was not intended for actual bearing use. 


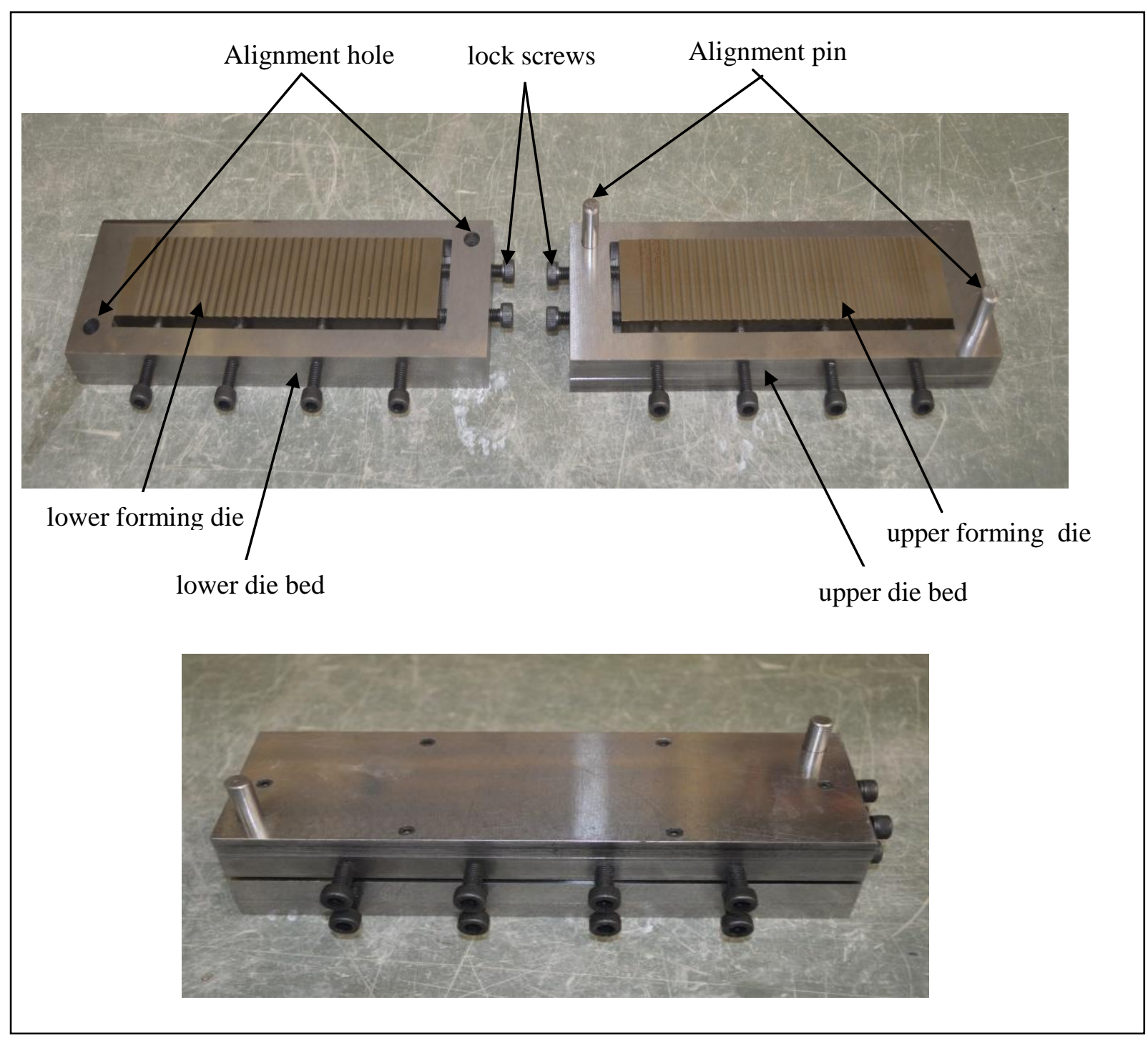

Figure 6: Bump foil forming tool at the University of Manchester

This final bump structure was placed on a rigid plate for testing (Figure 7). Due to potential distortion/damage from welding or soldering, the left hand end of the first bump was secured by retaining a flat tab and gluing this to the plate using epoxy (Figure 7(a)). Hence, the left-hand end of the first bump was not strictly-speaking fully fixed (since the latter means that a no-rotation condition is imposed at that end, as in Figure 2). Hence, for the purpose of comparing with experiment, the FE model was slightly altered by introducing a flat segment to the left of the first bump and fixing all nodes on it in the $x_{\mathrm{f}}, y_{\mathrm{f}}$ and $z_{\mathrm{f}}$ directions. A thin layer of oil was applied on the plate, where the other flat segments of the bump foil slide, to minimize the friction force in $x_{\mathrm{f}^{-}}$ direction. 


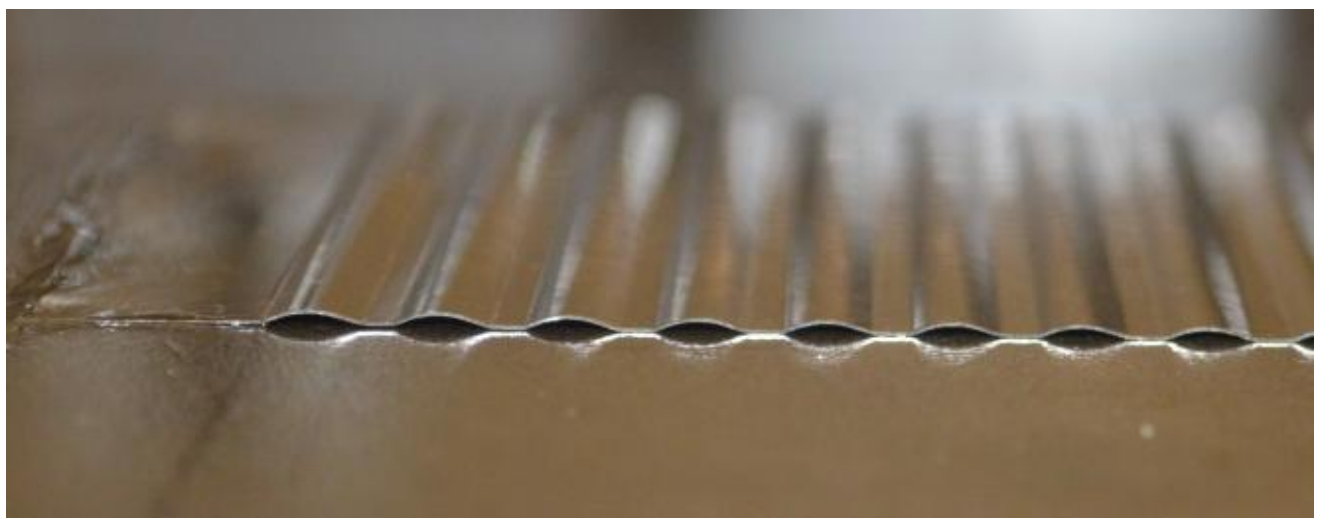

(a)

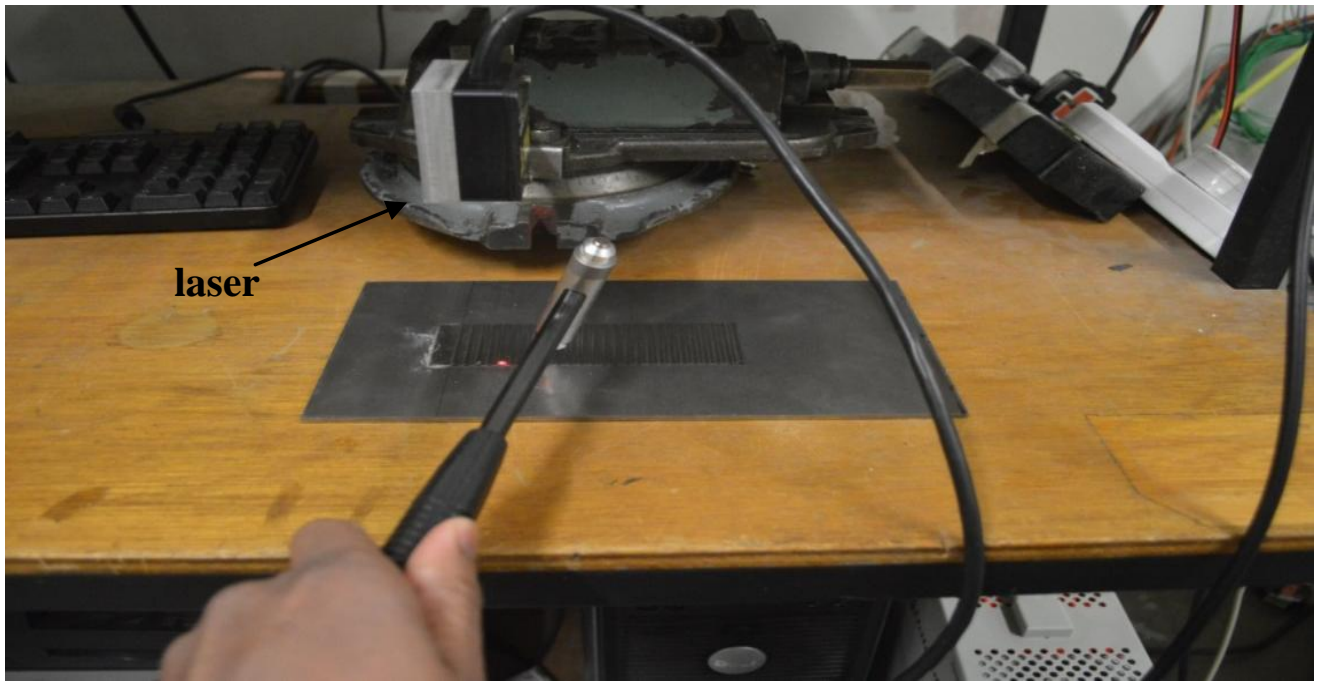

(b)

Figure 7: Experimental set-up: (a) close-up of finished foil; (b) impact testing using hammer and laser.

The experimental setup is shown in Figure $7(b)$. The excitation was applied in the radial $\left(y_{\mathrm{f}}\right)$ direction at the apex of one bump using an instrumented impact hammer (sensitivity $2.25 \mathrm{mV} / \mathrm{N}$ ) with a medium hammer tip. The displacement response in the radial direction at the apex of another bump was picked up by a laser displacement sensor with a sensitivity of $1 \mathrm{~V} / \mathrm{mm}$. It is noted that the mass of the bump foil structure was approximately 4 grams, and so, not even a miniature accelerometer would have been suitable since it would have significantly altered the dynamics of the structure. Figure 8(a) shows a typical receptance FRF (relating bumps nos. 5 and 7), obtained using a SignalCalc Dynamic Signal Analyzer running on Abacus hardware. The theoretical FRF is overlaid on the same axes. It is seen that the signal-to-noise ratio was rather poor for the second 
and higher modes. The reason for this was the need to keep the impacts gentle and to limit their number, thus avoiding permanent deformation to the delicate structure. In fact, the FRF was computed from the average of only two impacts, after several impacts were rejected due to poorly directed hits. Nonetheless, as can be seen from Figure 8(a) and the zoomed view in Figure 8(b), the measured FRF correlates reasonably well with the predicted FRF in the domain of the first mode up to the first anti-resonance. The first natural frequency was predicted at $1.799 \mathrm{kHz}, 4 \%$ less than the measured value $1.881 \mathrm{kHz}$. The theoretical FRF was obtained using 2D FE full harmonic response analysis (FHRA). The parameters were as shown in Figure 2 except that the density was slightly different $\left(8193 \mathrm{~kg} / \mathrm{m}^{3}\right.$ for Inconel 718$)$ and the left-hand constraint altered as described above. It is also noticed that the alteration of the constraint resulted in a reduction of the predicted fundamental natural frequency of not more than $6 \%(1.799 \mathrm{kHz} v s 1.908 \mathrm{kHz})$. 


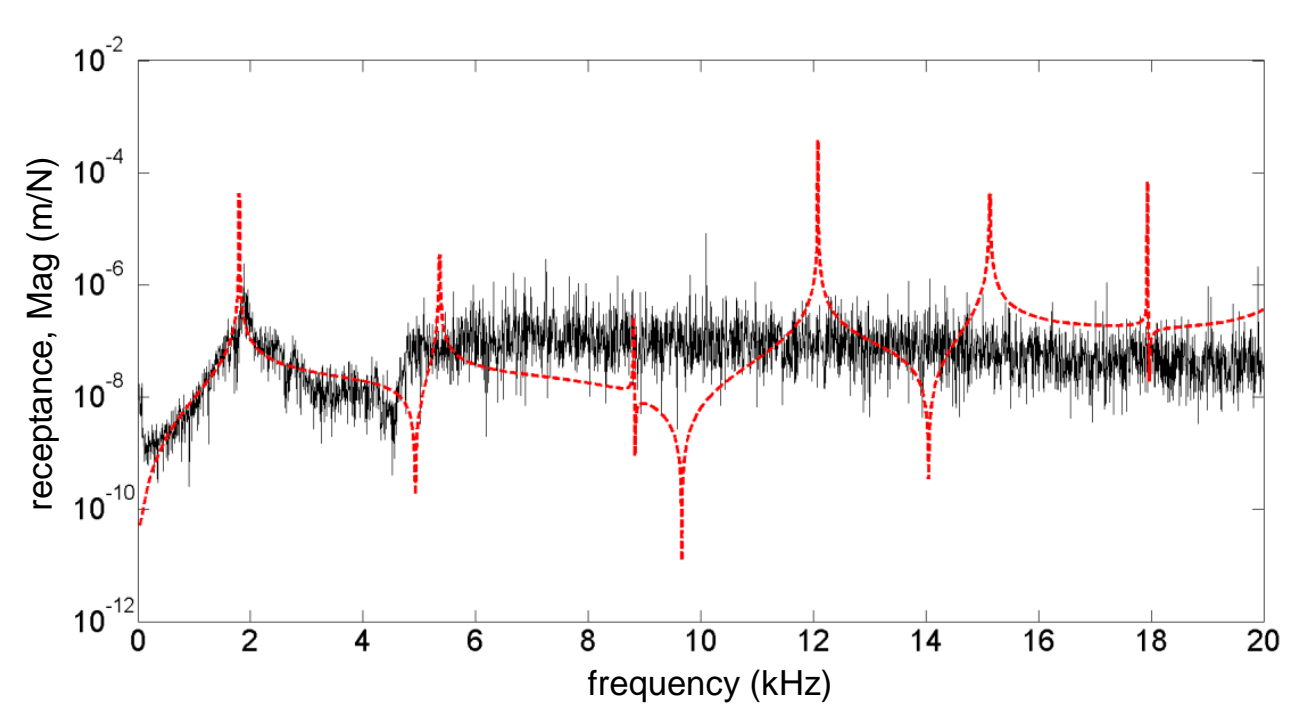

(a)

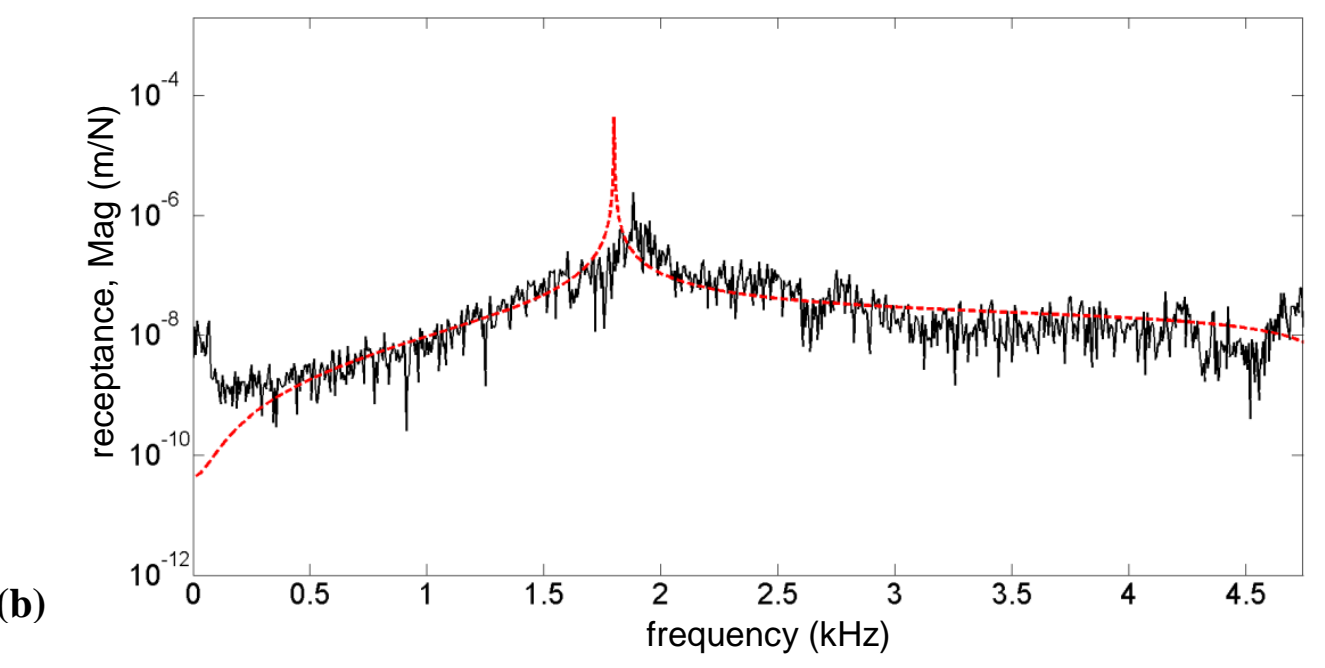

Figure 8: Receptance FRF $\alpha_{5 y_{\mathrm{f}}{ }_{y_{\mathrm{f}}}}(\omega)$ relating $y_{\mathrm{f}}$-displacement/excitation at apexes of bumps nos. 5 and 7 - FE analysis (2D element, FHRA) vs impact test: (a) 0-20 kHz; (b) zoomed view over 0-5 kHz (FE analysis $(----)$; measurement $(\longrightarrow)$

It should be noted that during the tests, the supporting plate was rested on a wooden-topped trolley with a steel structure on rubber wheels. In hindsight, a seismic block would have been more appropriate, ensuring that unwanted support structure dynamics do not affect the results. Figure 8(b) does not reveal any significant unpredicted resonance in the domain of the first mode. It is noted however that the experimental FRF diverges from the theoretical one for frequencies below 
$250 \mathrm{~Hz}$. Hence, after the review of the first draft of this paper, the authors mounted the same test piece on a seismic block and repeated the test to ascertain that this divergence was not due to the support structure dynamics. Unfortunately, by this time, the test piece had been significantly distorted - as can be seen in Figure 9(a), bump no.7 (where the impacts were applied) was somewhat squashed and the tabs to its right (over the middle portion) were no longer in contact with the supporting surface. For this reason, the new FRF (on seismic block) could not accurately replicate the original FRF (on desk), as can be seen in Figure 9(b). The divergence of the new measured FRF (purple) from the original measured FRF (black) above $3000 \mathrm{~Hz}$ was due to the distortion of the foil since the same behaviour was observed when the test was repeated with the distorted test piece placed on the desk again. However, there is good agreement between these two measured FRFs until $2000 \mathrm{~Hz}$ and divergence from the theoretical FRF for frequencies below 250 $\mathrm{Hz}$ is seen to occur with both measured FRFs. The accuracy of the theoretical model at low frequencies is confirmed in new section 6 , where it is validated against published results for the case of static (zero frequency) loading. Hence, the discrepancy between the theoretical and measured FRFs below $250 \mathrm{~Hz}$ must be due to some other issue with the measurement set-up. 


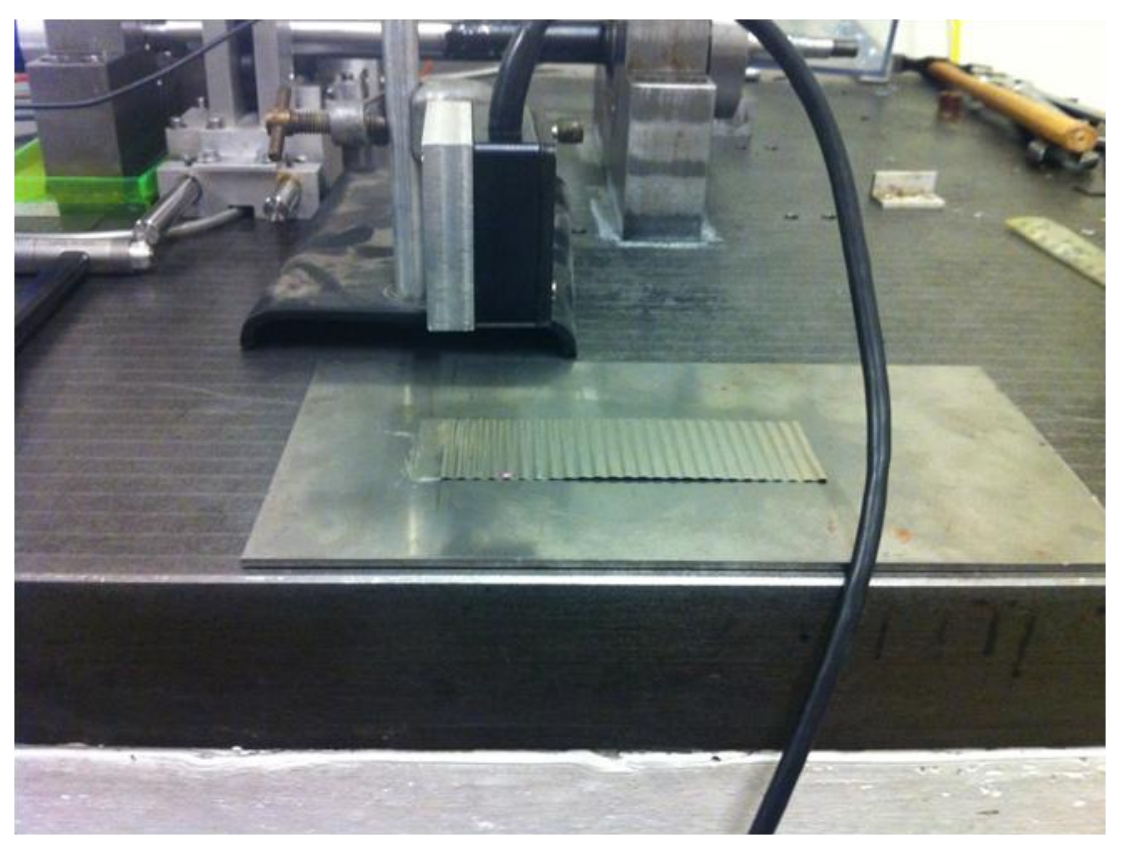

(a)

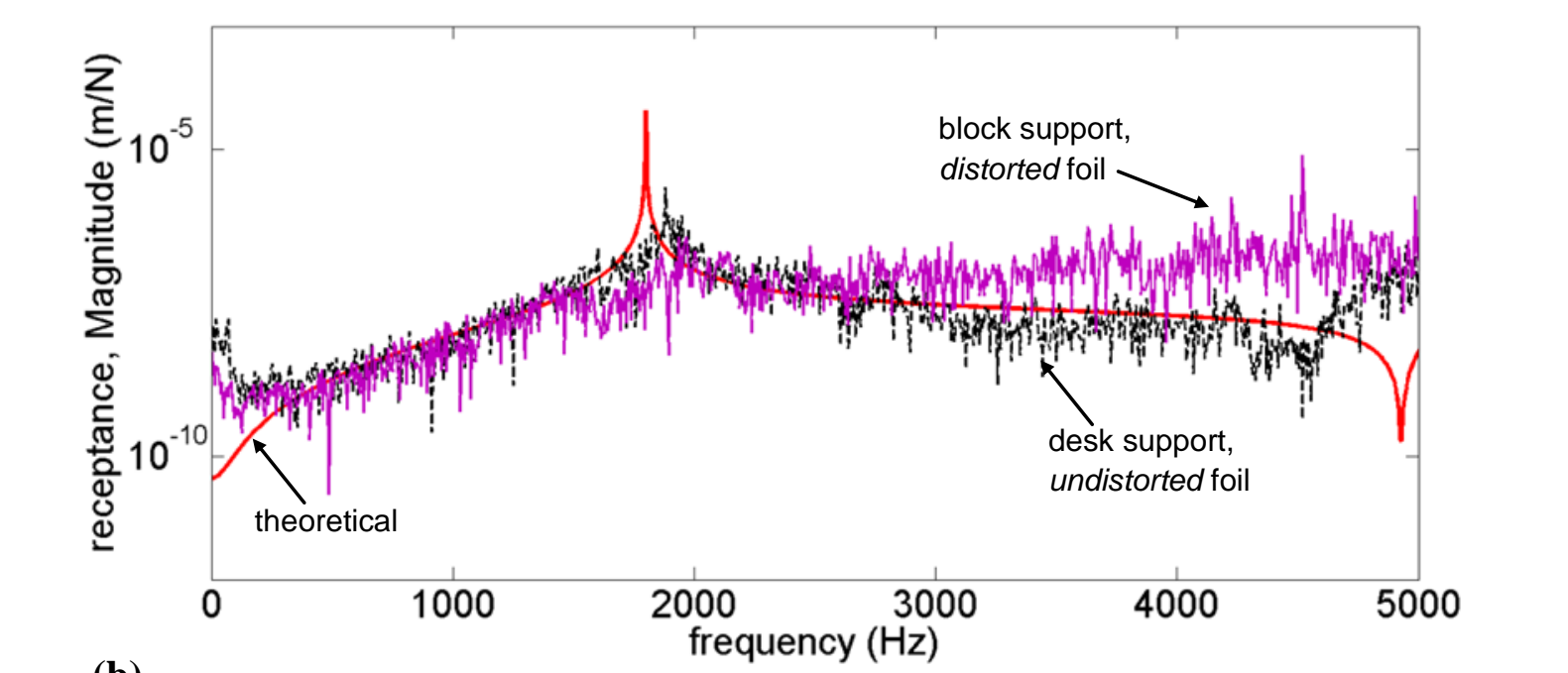

(b)

Figure 9: Measured FRFs vs theoretical FRF: black dotted - original measured on desk (undistorted foil); solid purple - newly measured on block (distorted foil); solid red theoretical. 


\section{INCLUSION OF FOIL MODAL MODEL INTO ROTOR-BEARING PROBLEM}

With reference to Figure 1, the equations governing the motion of the symmetric rigid rotor-FAB system with rotor of mass $m_{\mathrm{r}}$ per bearing rotating with angular velocity $\Omega$ can be written as:

$$
\varepsilon_{x}^{\prime \prime}=\frac{4}{m_{\mathrm{r}} c \Omega^{2}}\left(F_{x}+m_{\mathrm{r}} u \Omega^{2} \cos 2 \tau\right), \quad \varepsilon_{y}^{\prime \prime}=\frac{4}{m_{\mathrm{r}} c \Omega^{2}}\left(F_{y}+S+m_{\mathrm{r}} u \Omega^{2} \sin 2 \tau\right)
$$

where: $\tau=\Omega t / 2$ is the non-dimensional time and ()$^{\prime}$ denotes $\partial() / \partial \tau, \varepsilon_{x}=x_{\mathrm{J}} / c, \varepsilon_{y}=y_{\mathrm{J}} / c$ are the displacements of the journal $\mathrm{J}$ in the $x, y$ directions (relative to the bearing centre $\mathrm{B}$, which is assumed to be fixed) normalized by the radial clearance $c$ (which is the air gap when the journal is centralized in the bearing with no foil deflection), $S$ is the static load in the $y$ direction per bearing $\left(=-m_{\mathrm{r}} g\right.$, in this work, except in Section 6$)$, and $u$ the unbalance eccentricity. $F_{x}$ and $F_{y}$ are the airfilm reaction forces on the journal, obtained by integrating the air film pressure distribution over the bearing area [2, 3]. For a FAB of radius $R$ and length $L$ (Figure 1 ), let $p(\xi, \theta, \tau)$ denote the air film pressure (absolute) where $\xi=\frac{z_{\mathrm{f}}}{R}$. The pressure function is then governed by the isothermal Reynolds Equation (RE):

$$
\psi^{\prime}=\frac{1}{\Lambda}\left\{\frac{\partial}{\partial \theta}\left[\psi\left(\tilde{h} \frac{\partial \psi}{\partial \theta}-\psi \frac{\partial \widetilde{h}}{\partial \theta}\right)\right]+\frac{\partial}{\partial \xi}\left[\psi\left(\tilde{h} \frac{\partial \psi}{\partial \xi}-\psi \frac{\partial \widetilde{h}}{\partial \xi}\right)\right]\right\}-\frac{\partial \psi}{\partial \theta}
$$

where: $\Lambda$ is the bearing number $[2,3], \psi=\tilde{p} \tilde{h}, \tilde{p}=\frac{p}{p_{\mathrm{a}}}, p_{\mathrm{a}}$ being the atmospheric pressure and $\tilde{h}$ the non-dimensional air-film gap at a position $(\xi, \theta)[2,3]$ :

$$
\tilde{h}=1-\varepsilon_{x} \cos \theta-\varepsilon_{y} \sin \theta+\widetilde{w}
$$

$\widetilde{w}=\frac{w}{c}$ being the non-dimensional foil deflection in the radial direction at a position $(\xi, \theta)$. As in [2-7], and as justified by the agreement between the 2D and 3D FE mode shapes in Figure 3, it shall be assumed that the variation of the foil deflection in the axial $\left(z_{\mathrm{f}}\right)$ direction is negligible, meaning that $\widetilde{w}$ is a function of $\theta$ only. Also, as in most works e.g. [1-15], the stiffness and inertia of the top foil are neglected and it is assumed to be in contact with the bump at all times for the purpose of 
determining $\widetilde{w}$. For given $\theta, \widetilde{w}$ is obtained by interpolation from the $n_{\text {bumps }} \times 1$ vector $\mathbf{w}$ containing the radial displacements at the apexes of the bumps. It is proposed that $\mathbf{w}$ can in principle be expressed as a superposition of $n_{\mathrm{f}}$ bump foil structure modes:

$$
\mathbf{w}=-\mathbf{H}_{\mathbf{y}_{\mathbf{f}}} \mathbf{q}_{\mathbf{f}}(\tau), \mathbf{H}_{\mathbf{y}_{\mathbf{f}}}=\left[\begin{array}{lll}
\boldsymbol{\phi}_{\mathbf{y}_{\mathbf{f}}}^{(1)} & \cdots & \boldsymbol{\phi}_{\mathbf{y}_{\mathrm{f}}}^{\left(n_{\mathrm{f}}\right)}
\end{array}\right]
$$

where $\mathbf{q}_{\mathbf{f}}$ is the $n_{\mathrm{f}} \times 1$ vector of modal coordinates and $\boldsymbol{\phi}_{\mathbf{y}_{\mathbf{f}}}^{(r)}, r=1 \ldots n_{\mathrm{f}}$, is the $n_{\text {bumps }} \times 1$ massnormalised eigenvector in mode no. $r$ with natural frequency $\omega_{\mathrm{f}_{r}}(\mathrm{rad} / \mathrm{s})$, containing the radial displacements at the apexes of the bumps. It is noted that the elements in $\boldsymbol{\phi}_{\mathbf{y}_{\mathbf{f}}}^{(r)}$ are positive in the $+y_{\mathrm{f}}$ direction (see Figure 2), whereas the elements in $\mathbf{w}$ are positive when radially outward (corresponding to the $-y_{\mathrm{f}}$ direction). $\quad \mathbf{q}_{\mathbf{f}}$ is governed by the modal equations of the bump foil structure (expressed in terms of the non-dimensional time $\tau$ ):

$$
\left(\Omega^{2} / 4\right) \mathbf{q}_{\mathbf{f}}^{\prime \prime}+(\Omega / 2) \mathbf{D} \mathbf{q}_{\mathbf{f}}{ }^{\prime}+\Delta \mathbf{q}_{\mathbf{f}}=-\mathbf{H}_{\mathbf{y}_{\mathbf{f}}}^{\mathbf{T}} \mathbf{f}_{\mathbf{p}}
$$

where $\mathbf{f}_{\mathbf{p}}$ is the $n_{\text {bumps }} \times 1$ vector of air pressure forces on the bumps, obtained by averaging $p(\xi, \theta, \tau)$ over a bump projected area of $S_{\mathrm{p}} \times L$. D and $\Delta$ are the diagonal matrices:

$$
\mathbf{D}=\operatorname{diag}\left[\begin{array}{lll}
\cdots & 2 \zeta_{\mathrm{f}_{r}} \omega_{\mathrm{f}_{r}} & \cdots
\end{array}\right], \Delta=\operatorname{diag}\left[\begin{array}{lll}
\cdots & \omega_{\mathrm{f}_{r}}^{2} & \cdots
\end{array}\right]
$$

It is noted that this preliminary work is restricted by the assumption of linear damping in the foil structure. This means that the nonlinear friction forces in the circumferential $\left(x_{\mathrm{f}}\right)$ direction (see Figure 2) are not considered, but their equivalent viscous damping effect is accounted in the damping matrix $\mathbf{D}$, where $\zeta_{\mathrm{f}_{r}}$ is the viscous damping ratio of mode no. $r$. This is analogous to the equivalent viscous damping used in the case of spring-damper foil models e.g. [2-3, 5-7, 12]. It should be noted that the viscous damping used in spring-damper models e.g. [2-3, 5-7, 12] is actually an equivalent viscous damping coefficient based on a measured hysteretic damping loss factor and an assumed frequency (typically taken to be the rotational speed). In the present case, the equivalent viscous damping is assumed to conform to a proportional damping model since the 
model is modal [20]. Notwithstanding the above, the work in this section is adaptable to nonlinear friction forces with further development (section 4.1).

The analysis in section 2 (Figure 4) suggests that the circumferential displacements may be more accurately represented by modal superposition than the radial displacements. Hence, this motivates the development of an alternative to eq. (7) for the purpose of transforming from physical to modal coordinates, as a means of cross-checking. If $\mathbf{u}$ is the $n_{\text {bumps }} \times 1$ vector of the circumferential displacements at the apexes, then:

$$
\mathbf{u}=\mathbf{H}_{\mathbf{x}_{\mathbf{f}}} \mathbf{q}_{\mathbf{f}}(\tau), \mathbf{H}_{\mathbf{x}_{\mathbf{f}}}=\left[\begin{array}{lll}
\boldsymbol{\phi}_{\mathbf{x}_{\mathbf{f}}}^{(1)} & \cdots & \boldsymbol{\phi}_{\mathbf{x}_{\mathbf{f}}}^{\left(n_{\mathrm{f}}\right)}
\end{array}\right]
$$

where $\boldsymbol{\phi}_{\mathbf{x}_{\mathbf{f}}}^{(r)}, r=1 \ldots n_{\mathrm{f}}$, is the $n_{\text {bumps }} \times 1$ mass-normalised eigenvector in mode no. $r$ containing the circumferential displacements at the apexes of the bumps. Let $\mathbf{R}_{\mathbf{x}_{\mathbf{f}} \mathbf{y}_{\mathbf{f}}}(0)$ be the static (i.e. at zero frequency) receptance matrix relating the elements in $\mathbf{u}$ with those in $-\mathbf{f}_{\mathbf{p}}$. Likewise, let $\mathbf{R}_{\mathbf{y}_{\mathbf{f}} \mathbf{y}_{\mathbf{f}}}(0)$ be the static receptance matrix relating the elements in $-\mathbf{w}$ with those in $-\mathbf{f}_{\mathbf{p}}$. Then, temporarily neglecting foil inertia effects:

$$
\begin{gathered}
\mathbf{w}=\mathbf{R}_{\mathbf{y}_{\mathbf{f}} \mathbf{y}_{\mathbf{f}}}(0) \mathbf{f}_{\mathbf{p}} \\
\mathbf{u}=-\mathbf{R}_{\mathbf{x}_{\mathbf{f}} \mathbf{y}_{\mathbf{f}}}(0) \mathbf{f}_{\mathbf{p}} \Rightarrow \mathbf{w}=-\mathbf{R}_{\mathbf{y}_{\mathbf{f}} \mathbf{y}_{\mathbf{f}}}(0) \mathbf{R}_{\mathbf{x}_{\mathbf{f}} \mathbf{y}_{\mathbf{f}}}(0)^{-1} \mathbf{u}
\end{gathered}
$$

Hence, from (12) and (16):

$$
\mathbf{w}=-\mathbf{R}_{\mathbf{y}_{\mathbf{f}} \mathbf{y}_{\mathbf{f}}}(0) \mathbf{R}_{\mathbf{x}_{\mathbf{f}} \mathbf{y}_{\mathbf{f}}}(0)^{-1} \mathbf{H}_{\mathbf{x}_{\mathbf{f}}} \mathbf{q}_{\mathbf{f}}(\tau)
$$

The approach used to derive eq. (17) only partly neglects the foil inertia (as a result of the necessity of using the static receptance matrices). However, $\mathbf{u}$ itself is calculated on the basis of eqs. (12) and (9), which do take into account of the foil inertia. Of course, both approaches of eqs. (17) and (7) fully account for bump interaction. 
By discretizing the RE (eq. (5)) over a finite difference grid of $N_{\mathrm{z}} \times N_{\theta}$ points [3], eqs. (4), (5) and (9) can be expressed in the state-space form of eq. (1), where the number of state variables in the state vector $\mathbf{s}$ in eq. (1) is $n_{\text {state }}=N_{\mathrm{z}} \times N_{\theta}+2 n_{\mathrm{f}}+4$, comprising the FD-discretized values of $\psi$, the elements in $\mathbf{q}_{\mathbf{f}}$ and $\mathbf{q}_{\mathbf{f}}{ }^{\prime}$, and rotor state variables $\varepsilon_{x}, \varepsilon_{y}, \varepsilon_{x}{ }^{\prime}, \varepsilon_{y}{ }^{\prime}$ :

For comparative purposes, simulations are also performed using the independent spring-damper foil model (ISDFM). In this case, the $n_{\mathrm{f}}$ second order equations (9) are replaced by $n_{\text {bumps }}$ first order equations:

$$
\mathbf{w}^{\prime}=\left\{\mathbf{f}_{\mathbf{p}}-k_{\text {bump }} \mathbf{w}\right\} /\left(2 k_{\text {bump }} \eta\right)
$$

where, as in $[2-3,5-7,12]$, an equivalent viscous damper of $k_{\text {bump }} \eta / \Omega$, where $k_{\text {bump }}$ is the static stiffness of the bump (N/m) and $\eta$ is the loss factor. Hence, in the case of the ISDFM, the number of elements of the state vector $\mathbf{s}$ in eq. (1) is $n_{\text {state }}=N_{\mathrm{z}} \times N_{\theta}+n_{\text {bumps }}+4$.

In either case (modal model and ISDFM), the evolution of $\mathbf{s}$ with time is obtained by solving the system of equations (1) simultaneously in the time domain using an implicit integrator [3].

\subsection{Adaptability to Coulomb friction}

The scope of this paper is restricted to the extension of the simultaneous solution scheme for FAB rotor systems to include interaction between the bumps of the bump foil structure and its inertia. As already stated, the effect of the friction (between the top foil and bump apexes and between the flat part of bump foil and the bearing sleeve, as shown in Figure 10) is accounted as equivalent viscous damping (second term on the left hand side of eq. (9)), as in previous simultaneous solution analysis [2-3, 5-7]. The consideration of a Coulomb friction model is outside the scope of the present paper, but it is important to highlight the present method's adaptability to Coulomb friction. 


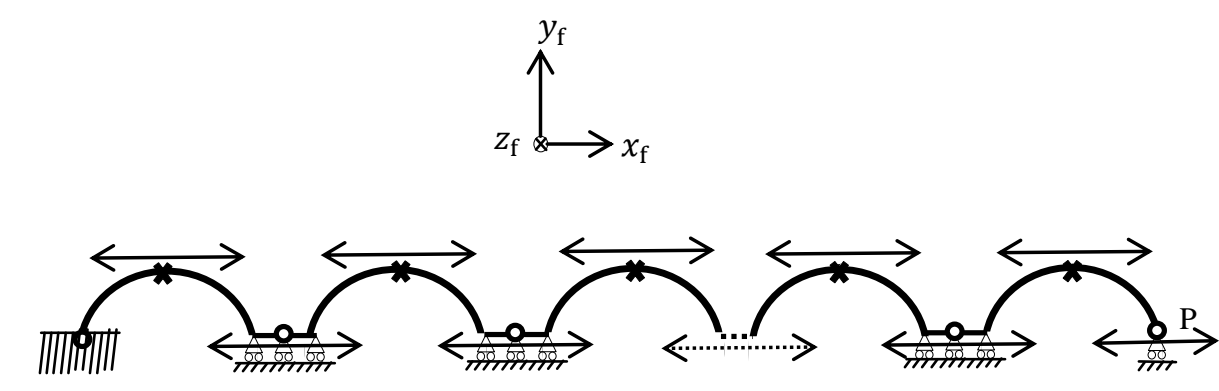

Figure 10: Friction forces on bump foil structure

The Coulomb friction model introduces a nonlinear effect on both the damping and effective stiffness of the bump foil structure. In [23], the nonlinear effect of the friction on the stiffness was modelled as a nonlinear constraint. Hence, in [23], both analytical and FE analysis of a bump foil model with nonlinear constraints was performed and the equivalent nonlinear spring stiffness of each bump was extracted. The damping effect of the friction was subsequently added as an equivalent (linear) viscous damper (as in the present paper) by the researchers in [23] when using the nonlinear bump springs in their FAB-rotor model.

On the other hand, Le Lez et al. [4], considered the nonlinear friction forces as external forces applied to the bump foil structure, which was therefore undamped linear elastic, just like that of the present paper, with similar constraints, but without inertia. Hence, the $N$-degree-of-freedom ("NDOF") model used in [4] was of the form

$$
\mathbf{f}=\mathbf{K}_{\mathrm{red}} \mathbf{V}
$$

where: $\mathbf{f}$ contained the radial (pressure) forces on the apexes and the friction forces indicated in Figure $10 ; \mathbf{v}$ contained the radial displacements at the apexes and the circumferential displacements corresponding to the friction forces in Figure $10 ; \mathbf{K}_{\text {red }}$ was a reduced form of the FE static linear 
stiffness matrix. Nonlinear expressions for the friction forces in $\mathbf{f}$ were then introduced in [4] to account for stick/slip conditions, which after combination with eq. (19) and manipulation, resulted in a system of state equations with the friction forces as state variables. Le Lez et al. [4] then solved the resulting system alongside the decoupled Reynolds Equation and rotor equations in a nonsimultaneous fashion.

In the present method, it is similarly possible to introduce the friction forces as an additional external excitation term on the bump foil (by adding an additional term $\mathbf{H}_{\mathbf{x}_{\mathbf{f}}} \mathbf{f}_{\mathbf{f}}$, where $\mathbf{f}_{\mathbf{f}}$ contains the friction forces only, on the right hand side of eq. (9), instead of the equivalent damping term on the left hand side of that equation), and introducing additional equations to express their nonlinearity. The modal matrices remain unchanged. However, the additional state variables in the resulting state-space system (eq.(1)) will entail the reworking of its Jacobian matrix, which is required by the implicit integrator for solving the resulting stiff system [3].

\section{DISCUSSION OF RESULTS OF FAB SIMULTANEOUS ROTOR SOLUTION}

In the simulations presented $n_{\mathrm{f}}=5$ modes of the system analysed in section 2 are used in foil modal model, eq. (9), which will henceforth be referred to as the full foil structure modal model (FFSMM) (see final paragraph of section 2.1). With regards to the ISDFM model, a loss factor value of $\eta=0.25$ is used in eq. (18), as in $[2,3,12]$. Hence, the equivalent viscous damping ratio $\zeta_{\mathrm{f}_{r}}$ used for all modes in FFSMM eq. (9) was half that (0.125), as per vibration theory in [20]. The full extent of the air film was covered by $15 \times 73$ FD grid. However, in view of the symmetry about the middle-section of the FAB, and periodicity in the $\theta$ direction, the actual values of $N_{\mathrm{z}}$ and $N_{\theta}$ used in the solution were just 7 and 72 respectively. Hence, in the case of the FFSMM solution, the number of state equations was 518. In the case of the ISDFM solution (with 26 bumps), the number of equations was 534. In the ISDFM, $k_{\text {bump }}=0.96 \mathrm{MN} / \mathrm{m}$, as mentioned in section 2 . As 
in [1], $m_{\mathrm{r}}=3.061 \mathrm{~kg}$, bearing radius $R=19.05 \mathrm{~mm}$, bearing length $L=38.1 \mathrm{~mm}, p_{\mathrm{a}}=101325$ $\mathrm{Pa}$, air viscosity $\mu=1.95 \times 10^{-5} \mathrm{Ns} / \mathrm{m}^{2}$ and the undeformed foil clearance $c=32 \times 10^{-6} \mathrm{~m}$. The static load per bearing in the $y$-direction $S=-m_{\mathrm{r}} g$.

Figure 11(a) shows the transient trajectory of the journal (from "default" initial conditions corresponding to zero journal centre displacements and velocities, air film at atmospheric pressure and undeformed foil) over 30 shaft revolutions, for the case of zero unbalance at 10,000 rpm, as calculated using the FFSMM solution. It is seen that the trajectory converges to a stable static equilibrium position. Figure 11(a) also shows the clearance deformation (due to the foil deflection) at the instant of maximum shaft eccentricity. Figure 11(b) shows the corresponding result from the ISDFM. Comparing Figures 11(a) and (b) it is seen that the solutions are comparable but significantly different. The foil deflection is higher with ISDFM and the ISDFM solution converges to a static equilibrium journal position that is at a lower level than that obtained by the FFSMM. This is also evident from the Figure 11(c), which shows, on the same axes, the steadystate conditions (static equilibrium journal positions and corresponding clearance deformations) for the FFSMM and ISDFM solutions. This observation was consistent over the speed range considered. The likely reason for this is that the radial stiffness of the full foil structure was seen in section 3.1 to be consistently higher than that of an independent simply supported bump, as a result of bump interaction and the weld at one end of the foil. A static equilibrium and stability analysis, as done in $[2,3]$ (based on an eigenvalue analysis of the Jacobian matrix of the state-space equations), revealed that, in the case of the ISDFM, the static equilibrium configuration becomes unstable to small perturbations beyond a speed of 14,791 rpm, whereas in the case of the FFSMM the static equilibrium configuration becomes unstable beyond 13,587 rpm. The reason for the lower instability threshold speed with FFSMM is again likely to be the higher overall foil stiffness in the FFSMM case since a lower stiffness was found in [3] to promote stability of the static equilibrium. 

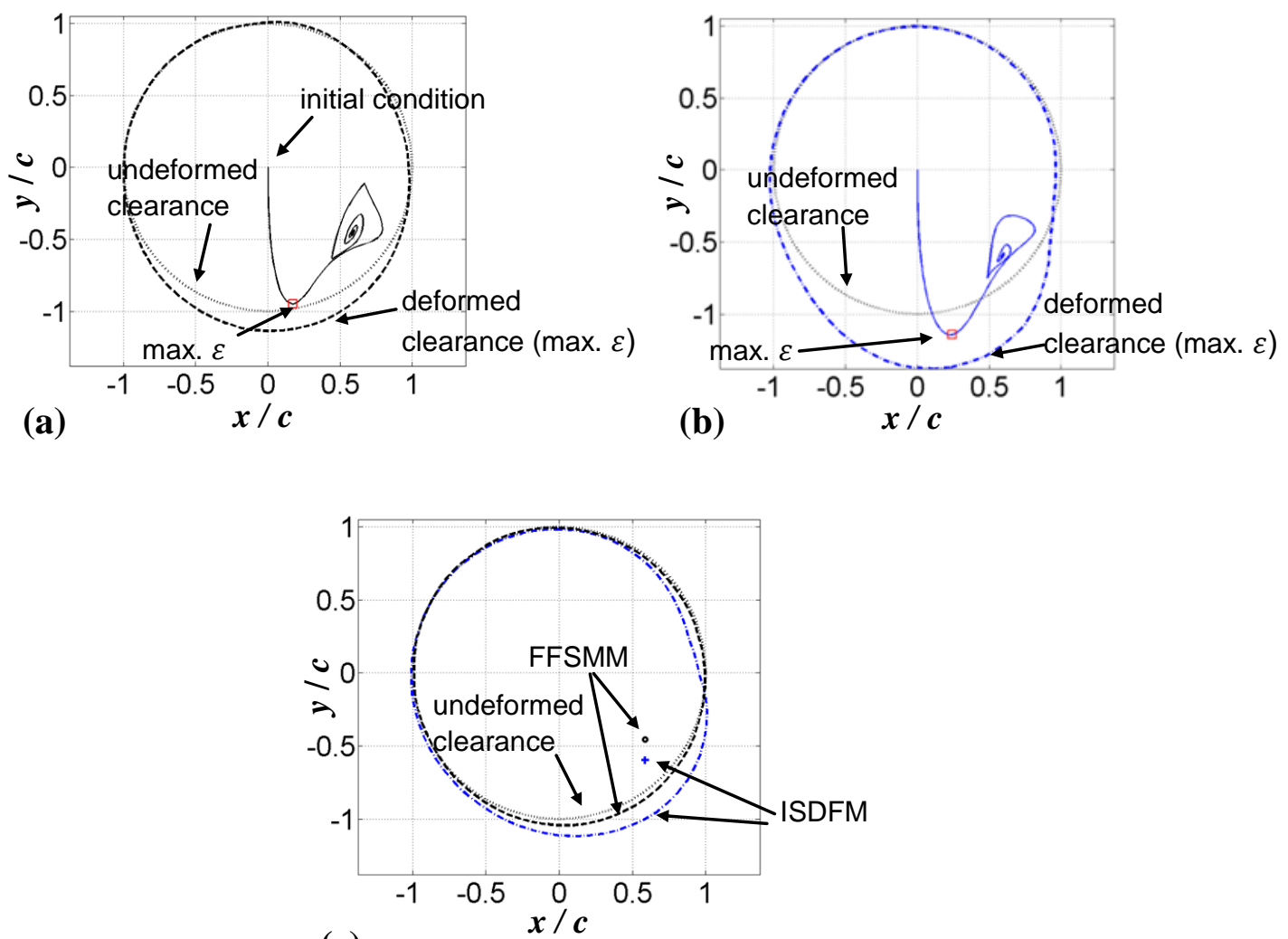

(c)

Figure 11: Response at 10,000 rpm and no unbalance $\left(m_{\mathrm{r}} u=0\right)$ : (a) transient journal trajectory over 30 revs and clearance deformation (FFSMM); (b) transient journal trajectory over 30 revs and clearance deformation (ISDFM); (c) steady-state response by FFSMM and ISDFM (clearance deformations in (a) and (b) are at the instant of maximum journal eccentricity $\varepsilon$ ).

Figure 12 shows the steady-state journal orbits, over a period covering 30 shaft revs, and the corresponding clearance deformations at the instant of maximum journal eccentricity, for four speeds in the range 10,000 to $13,000 \mathrm{rpm}$, when an unbalance of $m_{\mathrm{r}} u=10 \mathrm{~g} \cdot \mathrm{mm}$ is applied. With regard to the first three speeds $(10,000$ to $12,000 \mathrm{rpm}$, Figures $12(\mathrm{a}-\mathrm{c}))$, it is observed that the ISDFM gives larger orbits and higher foil deflection. The fundamental frequency of the orbits shown in Figure 12 is synchronous with the excitation. Such a steady-state orbit could not be achieved at 13,000 rpm for the FFSMM (which is why only the ISDFM solution is shown Figure 12(d)). However, the FFSMM did give a steady-state orbit with synchronous fundamental for 
lower levels of unbalance at $13,000 \mathrm{rpm}$ (e.g. $\left.m_{\mathrm{r}} u=5 \mathrm{~g} \cdot \mathrm{mm}\right)$. It is noted that this speed is quite close to the instability threshold speed $(13,587 \mathrm{rpm})$ for the FFSMM. The instigation, at high unbalance levels, of sub-synchronous activity in a speed regime of stable static equilibrium has been observed experimentally elsewhere e.g. [7]. Moreover, in this particular case it was noted that, with the FFSMM, for the case of no unbalance $\left(m_{\mathrm{r}} u=0 \mathrm{~g} \cdot \mathrm{mm}\right)$, two steady-state conditions were possible at 13,000 rpm: (i) a static equilibrium condition that could be reached from initial conditions corresponding to the static condition at 12,000 rpm (the latter being reachable from the "default" initial conditions used in Figure 12(a)); (ii) a self-excited subsynchronous oscillation (limit cycle) that could be reached directly from the "default" initial conditions used in Figure 12(a)).

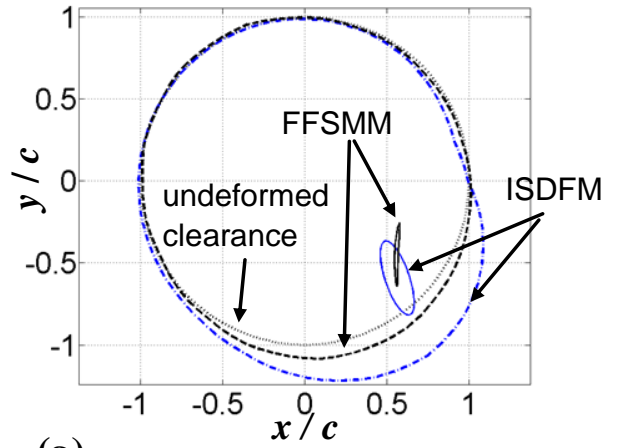

(a)

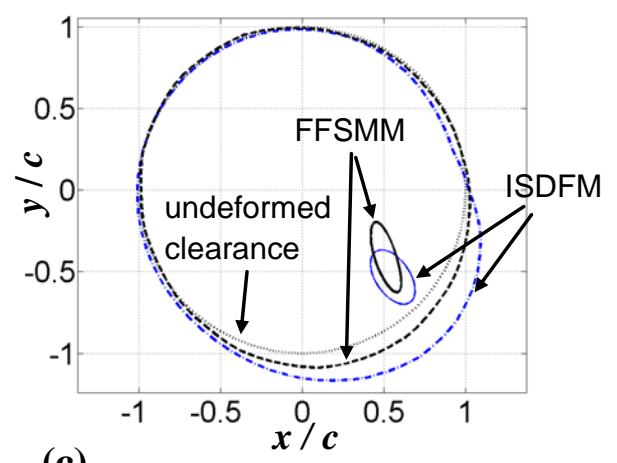

(c)

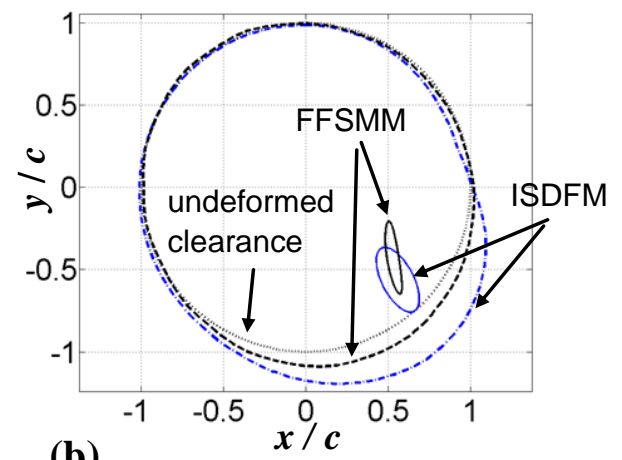

(b)

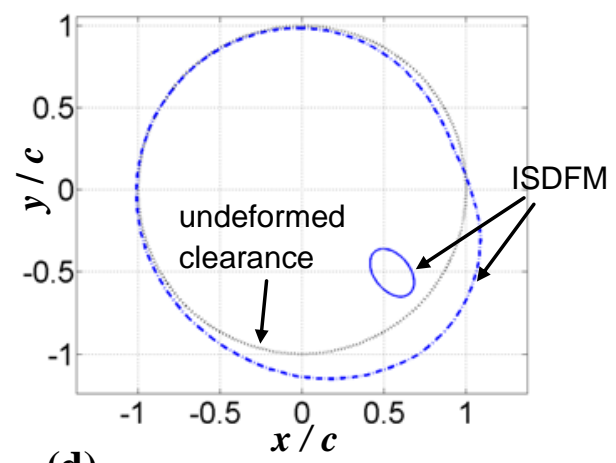

(d)

Figure 12: Steady-state unbalance response and clearance deformation (at the instant of maximum journal eccentricity $\varepsilon$ ) over the range 10,000 to $13,000 \mathrm{rpm}$ (orbits cover a period of 30 revs) with $m_{\mathrm{r}} u=10$ g.mm: (a) 10,000 rpm; (b) 11,000 rpm; (c) 12,000 rpm; (d) 13,000 rpm. 
The FFSMM results in Figures 11 and 12 were based on the foil deflection calculated using eq. (17) (the foil deflection determines the air film gap variation, eq. (6), used in the state equations defining the discretised form of the RE, eq. (5)). Repetition of the calculations using the original modal superposition equation for the foil deflection (eq. (7)), instead of eq. (17), produced closely agreeing results, as can be seen in Figures 13 (a-d).

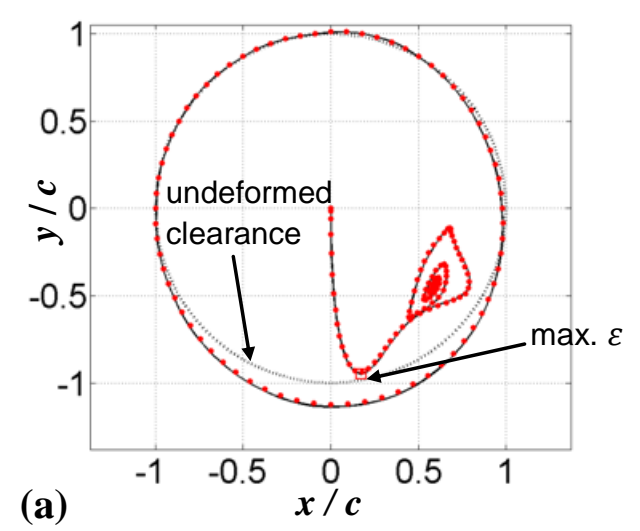

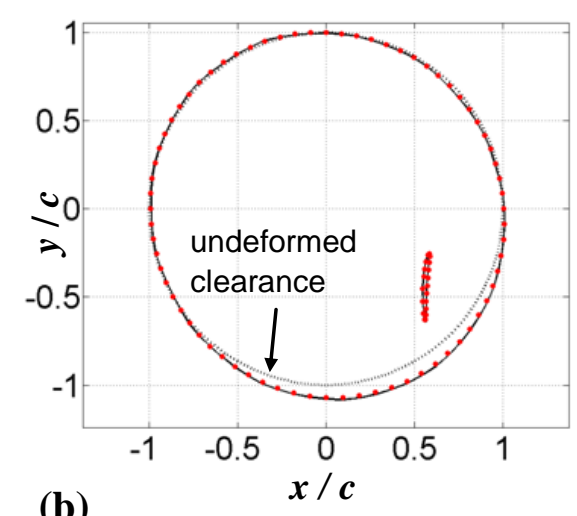

(b)

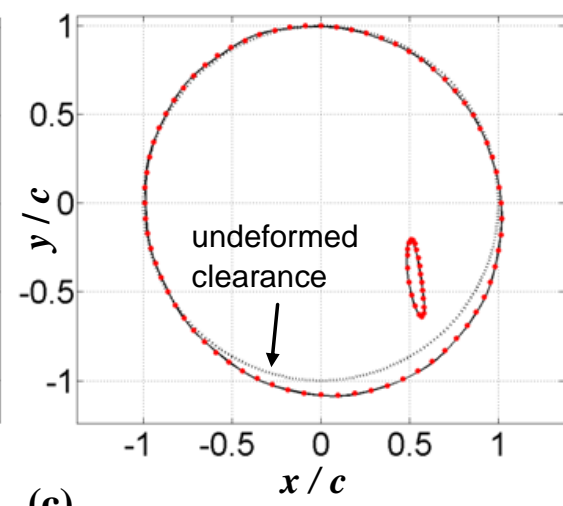

(c)

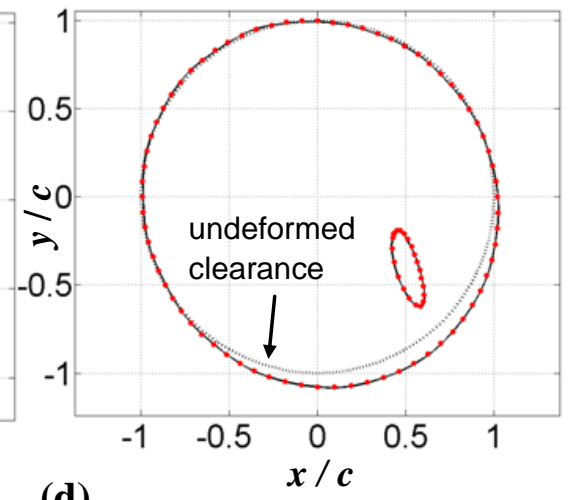

(d)

Figure 13: Comparison of FFSMM calculations using two alternative methods for calculation of the foil deflection (eq. (7) (••••); eq. (17) ( )): (a) transient response at 10,000 rpm and no unbalance $\left(m_{\mathrm{r}} u=0\right)$; (b-d) steady-state unbalance response with $m_{\mathrm{r}} u=10 \mathrm{~g} . \mathrm{mm}$ for 10,000 rpm, 11,000 rpm and 12,000 rpm respectively (clearance deformations shown are at the instant of maximum journal eccentricity $\varepsilon$ ).

As a final verification of the FFSMM, the foil deflections shown in Figures 11 and 12 were checked against quasi-static deflections obtained using eq. (14) and the air pressure forces $\mathbf{f}_{\mathbf{p}}$ as used by the 
time domain integrator in the FFSMM i.e. based on the $\psi=\tilde{p} \tilde{h}$ state variables where the $\widetilde{w}$ in the $\tilde{h}$ (eq. (6)) was determined by modal superposition using either eq. (17) or eq. (7). Figure 14 shows the result of such a check for 12,000 rpm in both the balanced (Figures 14(a,b)) and unbalanced (Figure 14(c)) conditions. The alternative results for foil deflection are seen to be reasonably close, as expected, since eq. (14) neglects foil inertia and foil inertia effects are not expected to be significant in the cases shown. In the balanced case $\left(m_{\mathrm{r}} u=0\right)$ foil inertia is only temporarily relevant in the transient stage (Figure 14(a)) and becomes completely irrelevant once the static equilibrium condition is reached (Figure 14(b)). In the steady-state unbalanced case (Figure 14(c)) foil inertia is unlikely to be significant since the excitation frequency of $200 \mathrm{~Hz}(12,000 \mathrm{rpm})$ is well below the foil first resonance of $1.9 \mathrm{kHz}$. The checks in Figure 14 also serve as verification for the ability of the reduced modal model of the foil to capture the bump interaction effect (that is accounted for in eq. (14)). 

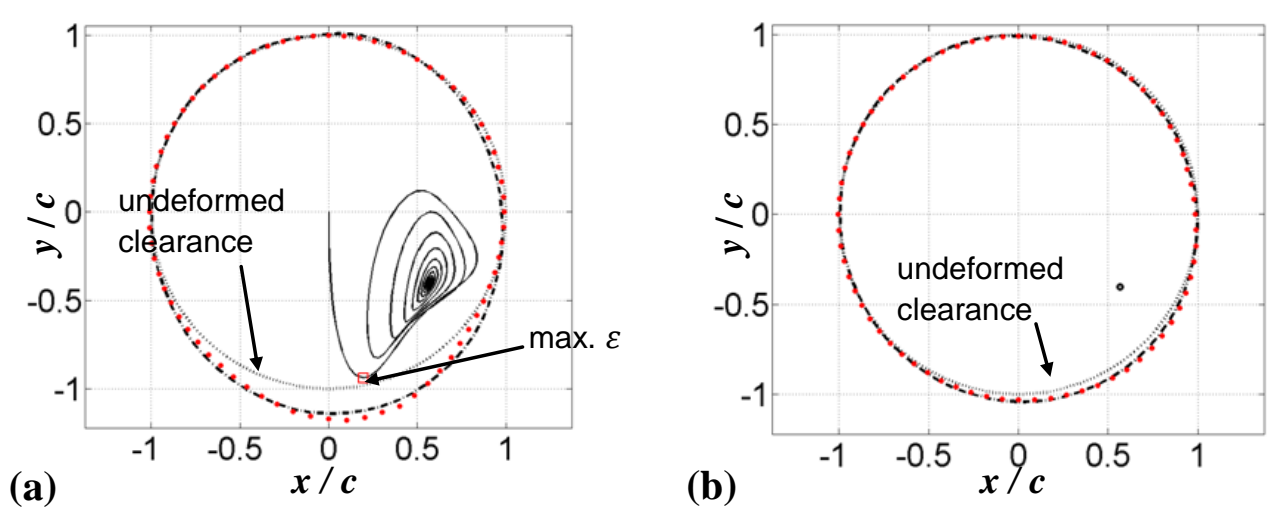

(b)

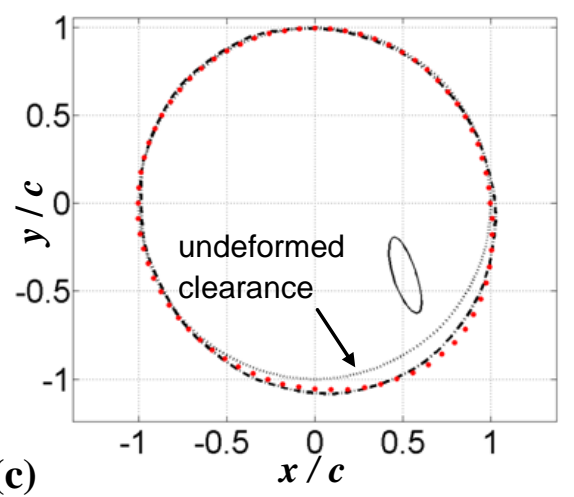

Figure 14: Foil deflection check - comparison between FFSMM solver output (based on modal superposition) (-·-•) and the quasi-static deflection (eq. (14)) ( $\cdots \cdots \cdot$ ): (a) $m_{\mathrm{r}} u=0,12,000 \mathrm{rpm}$, transient stage; (b) $m_{\mathrm{r}} u=0,12,000 \mathrm{rpm}$, steady-state condition (c) $m_{\mathrm{r}} u=10 \mathrm{~g} \cdot \mathrm{mm}, 12,000 \mathrm{rpm}$, steady-state condition (foil deflections in (a) and (c) are at instant of maximum journal eccentricity $\varepsilon$ ).

\section{VALIDATION OF ROTOR-BEARING MODEL AGAINST PUBLISHED RESULTS}

In 1978, NASA researchers Ruscitto et al. [24] published experimental data for the standard firstgeneration bearing used in this paper. This data has continued to be used by researchers to validate their bearing models, including Kim and San Andres (2005) [25], Xu et al. (2011) [16] and Le Lez et al. (2009) [4]. Ruscitto et al. measured the minimum air film thickness under steady-state static loading condition (no applied unbalance) over a range of static loads (per bearing) $10 \mathrm{~N}<|S|<$ $200 \mathrm{~N}$, for a given rotational speed. In this section, the present rotor-bearing model is applied to this problem. The static equilibrium condition at a given rotational speed was obtained directly 
(without numerical integration) by setting $\mathbf{s}^{\prime}=\mathbf{0}$ in eq. (1) and finding the solution $\mathbf{s}=\mathbf{s}_{\mathbf{E}}$ of the resulting system of nonlinear algebraic equations $\left.\chi(\tau, \mathbf{s})\right|_{m_{\mathrm{r}} u=0}=\mathbf{0}$, whose left hand side is a nonlinear vector function of $\mathbf{s}$ only (since the unbalance forcing terms in eqs. (4a,b) are omitted), following the process described in [3]. The minimum air film thickness could then be calculated from eq. (6) from the journal position and foil deflection. It is noted that, in accordance to the data in [24], for the calculations of this section, the Young Modulus of the foil material, the undeformed foil radial clearance, and the air viscosity were slightly adjusted to $214 \times 10^{9} \mathrm{~N} / \mathrm{m}^{2}, 31.8 \times 10^{-6}$ $\mathrm{m}, 1.82 \times 10^{-5} \mathrm{Ns} / \mathrm{m}^{2}$ respectively.

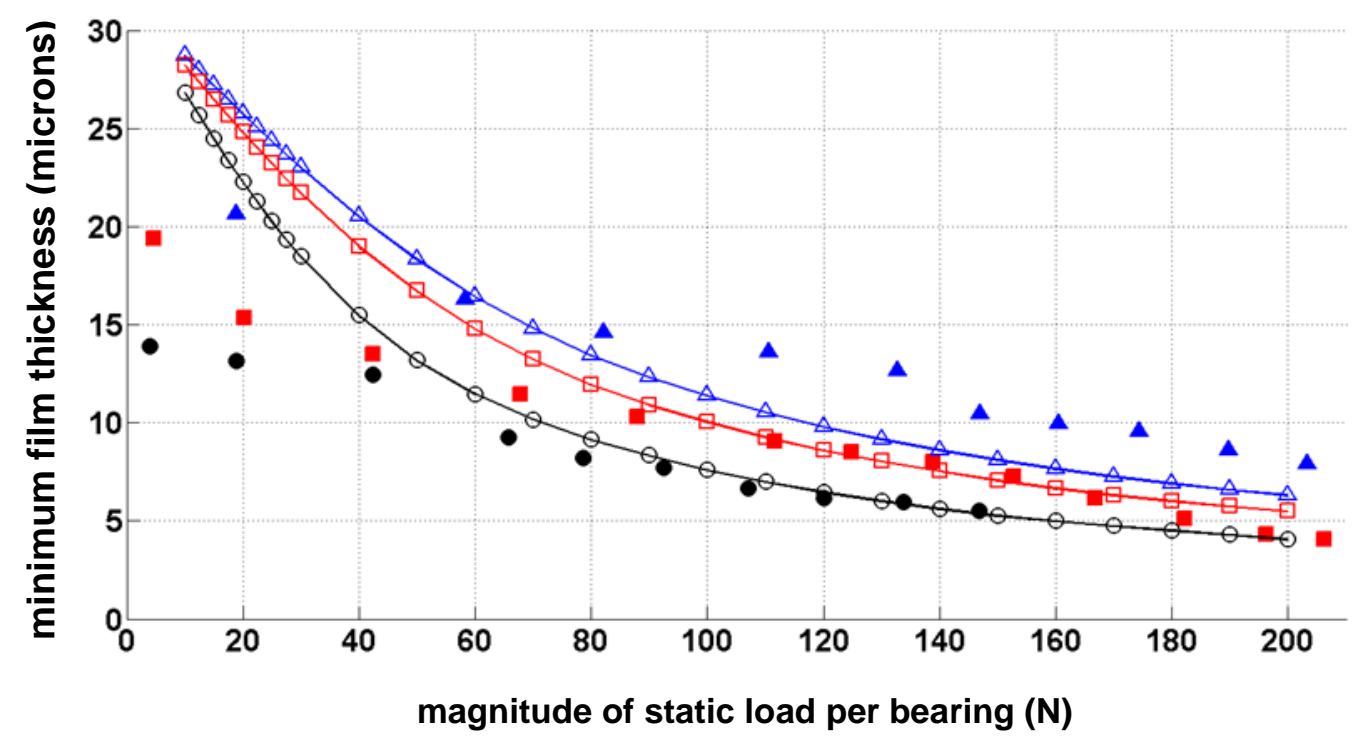

Figure 15: Variation of steady-state minimum air film thickness with static load for a given rotational speed: measurements [24] at 30,000 $\mathrm{rpm}(\bullet$ ), 45,000 $\mathrm{rpm}(\boldsymbol{\bullet}), 55,000 \mathrm{rpm}(\boldsymbol{\Delta})$;

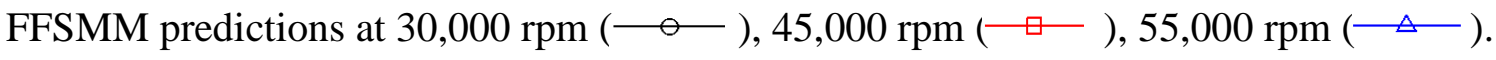

Figure 15 compares the predictions for minimum film thickness obtained with the FFSMM with the measurements for three speeds (30 krpm, $45 \mathrm{krpm}$ and $55 \mathrm{krpm}$ ). The correlation is satisfactory for the first two speeds for static loads above $60 \mathrm{~N}$. In fact, the predictions for these two speeds are virtually identical over the entire load range to those obtained by Le Lez et al. [4] with their "NDOF" inertia-less bump interaction foil model (see section 4.1). For the case of these two speeds 
(30 krpm, $45 \mathrm{krpm}$ ), Le Lez et al. [4] explain the poor correlation with experiment for loads below $60 \mathrm{~N}$ as the result of the foil structure playing a less significant part at lighter loads (i.e. the air film, which is more difficult to model accurately, is more influential at the lighter loads). With regard to the speed of $55 \mathrm{krpm}$, the correlation is generally not as good as the other two speeds (see Figure 15). Nonetheless, the theory follows the experimentally observed trend that for a given load, the minimum film thickness increases with speed. It is noted that none of the other three researchers [4, $16,25]$, who used Ruscitto et al.'s experimental data, presented their results at this particular speed (55 krpm).

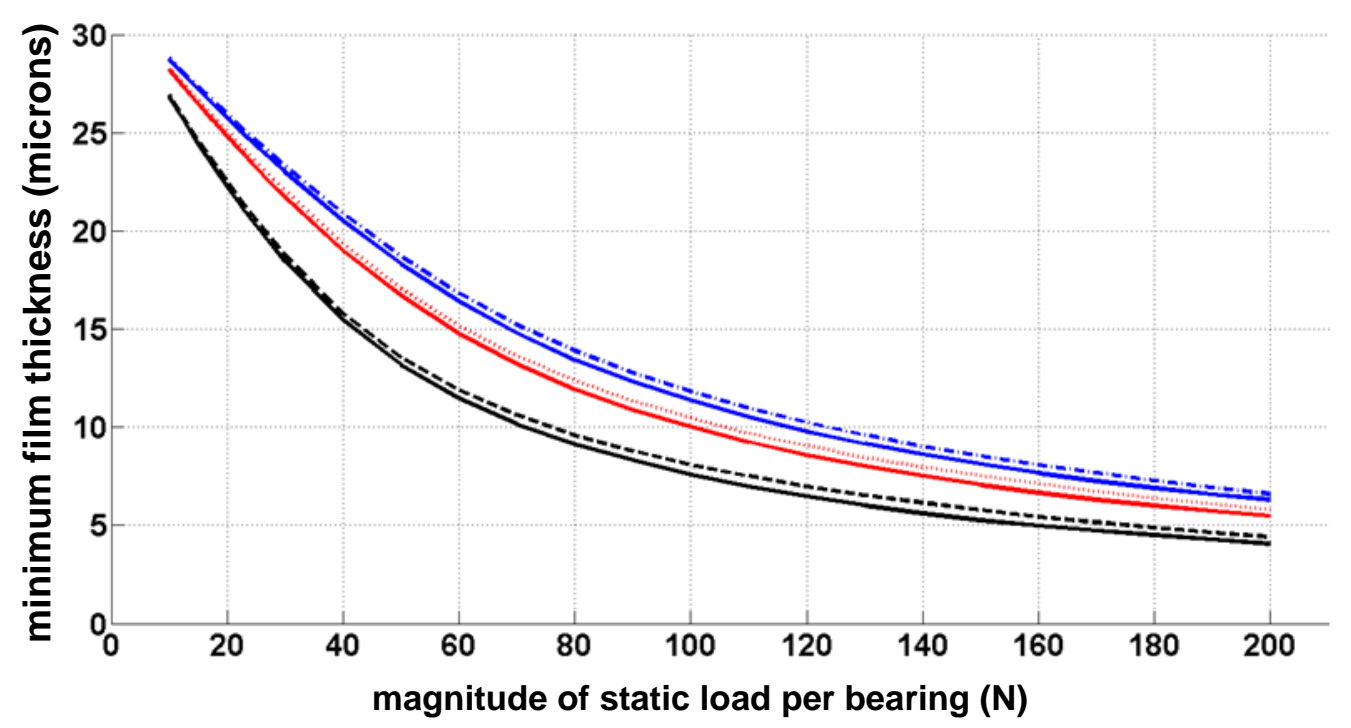

Figure 16: Variation of steady-state minimum air film thickness with static load for a given rotational speed: FFSMM predictions at 30,000 rpm (-), 45,000 rpm $(\square), 55,000 \mathrm{rpm}(\square)$;

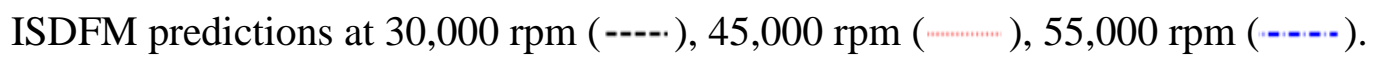

Figure 16 shows that the use of the ISDFM in lieu of the FFSMM results in only a slight difference in the prediction of the minimum film thickness. This finding agrees with the results of Le Lez et al. [4], who compared the minimum film thickness predictions with their NDOF model with those obtained by Iordanoff's formula [25], which is akin to the ISDFM. Nonetheless, the locus of static equilibrium journal positions over a range of static loads (at a given speed) predicted by FFSMM is 
markedly different from that predicted by ISDFM, as shown in Figure 17(a). This is in line with the findings of the Section 5 where the journal's static equilibrium by FFSMM was found to be consistently at a higher level than that predicted by the ISDFM as a result of the higher stiffness introduced by bump interaction. Moreover, the loci in Figure 17(a) agree well with those obtained by Le Lez et al. in [4], who compared their NDOF model predictions (equivalent to the FFSMM) with those from Iordanoff's formula (equivalent to the ISDFM) (see Figure 17(b), which is reproduced from [4] - this figure also shows the loci for a plain (rigid clearance) air bearing, which is not covered in this paper). It is noted that, as in section 5, the FFSMM results in this investigation use the modal properties accounting for bearing curvature (section 2.1). The very good agreement between the FFSMM results in Figure 17(a) and the NDOF model results in Figure 17(b) (which neglect bearing curvature) confirms that bearing curvature is not influential for this size bearing.

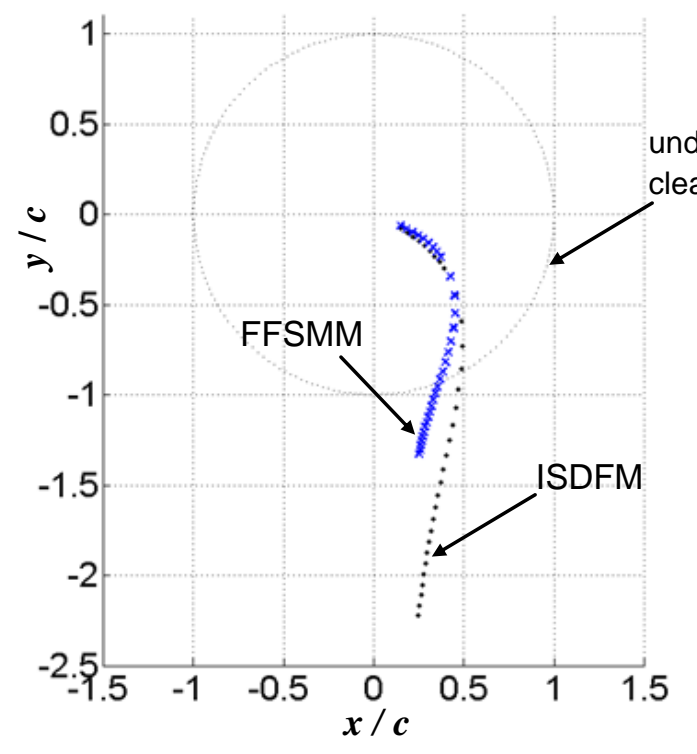

(a)

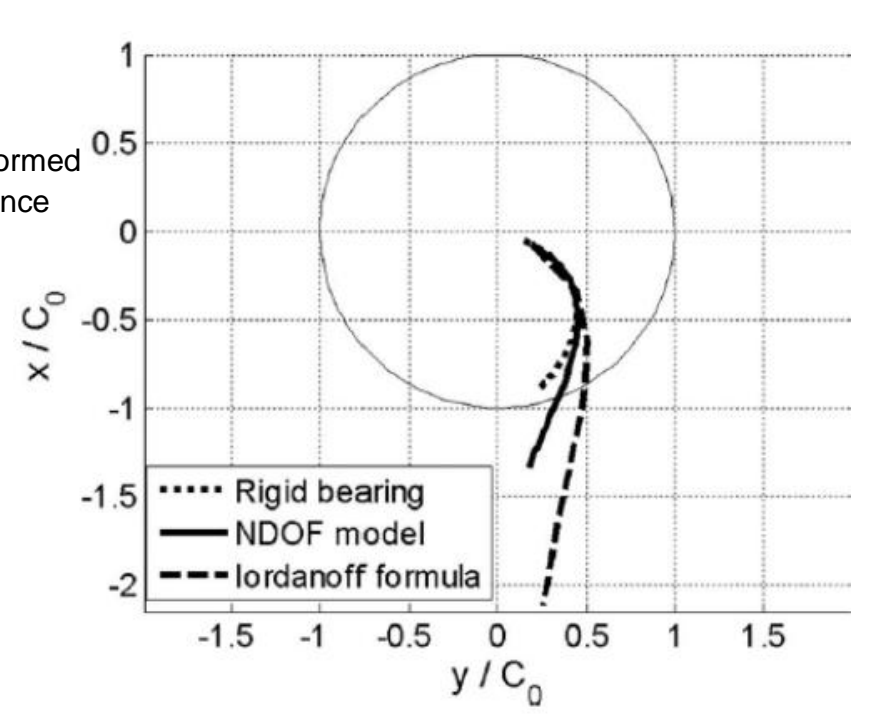

(b)

Figure 17: Predicted locus of journal static equilibrium positions at 30,000 rpm for static loads in the range $10 \mathrm{~N}$ to $260 \mathrm{~N}$ : (a) FFSMM (crosses), ISDFM (dots); (b) from Le Lez et al. [4]. 
The results in Figures 15-17 have served to validate one of the main qualifying features of the FFSMM i.e. bump interaction, which is the only feature that is relevant in the static equilibrium condition (i.e. zero frequency). Inertia and viscous damping in the FFSMM are not relevant to the present static equilibrium case. On the other hand, the NDOF bump foil model used in [4] was inertia-less but included Coulomb friction forces as external forces (see section 4.1). Hence, the excellent agreement between the proposed FFSMM and the NDOF model of [4] suggests that the Coulomb friction model used in [4] has little effect on the static equilibrium condition.

\section{CONCLUSIONS}

This paper has shown that the dynamics of the full foil structure of a first generation foil-air bearing, including bump interaction and foil inertia, can be represented by a reduced modal model (comprising five modes in the case considered). This full foil structure modal model (FFSMM) was based on an FE analysis that was experimentally validated. The FFSMM was successfully integrated into the previously developed simultaneous solution technique for the coupled foil, airfilm and rotor equations. The FFSMM results obtained were proven to be sound by comparison against those obtained using the independent spring-damper foil model, and by cross-correlating alternative methods for computing the foil deflection. The FFSMM was also validated against experimental and theoretical results published in the literature for the static equilibrium condition. A subsequent paper shall validate the model under unbalance response conditions using a purposebuilt test rig. This proof of principle opens the way for the inclusion of more complex foil structures (Generation II, III designs) into the simultaneous solution scheme (which until now was restricted to simple spring-damper models), while preserving its efficiency. While bump interaction was seen to be significant (raising the effective stiffness), foil inertia effects were not likely to be important in the unbalance response cases considered, due to the relatively low speeds. However, they are likely to be relevant in the case of high speed machinery, like turbochargers, since the 
experimentally validated fundamental frequency of the typical bump foil structure considered $(\sim 1.9$ $\mathrm{kHz}$ i.e. 114,000 rpm) is well within their operating speed range. Indeed, the present study ignored the inertia of the top foil, which would further reduce the fundamental frequency of the foil structure. The modal model in the present work could be augmented to include the dynamics of the top foil. Also, as described in this paper, the presented model is adaptable to a more advanced Coulomb friction model (instead of the assumed equivalent viscous damping model).

\section{ACKNOWLEDGMENTS}

The authors acknowledge the financial support of The Ministry of Education Malaysia and University of Malaysia Pahang. The project also benefited from the facilities and expertise generated by project EP/I029184/1 that was funded by the Engineering and Physical Sciences Research council (EPSRC), which the authors gratefully acknowledge.

\section{REFERENCES}

[1] M.F. Bin Hassan, P. Bonello, A neural network identification technique for a foil-air bearing under variable speed conditions and its application to unbalance response analysis, Journal of Tribology, accepted manuscript (April 2016) doi:10.1115/1.4033455.

[2] P. Bonello, H. M. Pham, The efficient computation of the nonlinear dynamic response of a foilair bearing rotor system, Journal of Sound and Vibration, 333(15) (2014) 3459-3478 doi: 10.1016/j.jsv.2014.03.001

[3] P. Bonello, H. M. Pham, Nonlinear dynamic analysis of high speed oil-free turbomachinery with focus on stability and self-excited vibration, Journal of Tribology, 136(4) (2014) 041705041705-10 doi:10.1115/1.4027859 
[4] S. Le Lez, M. Arghir, J. Frêne, Nonlinear numerical prediction of gas foil bearing stability and unbalanced response, Journal of Engineering for Gas Turbines and Power, 131(1) (2009) 012503 doi:10.1115/1.2967481

[5] J.S. Larsen, I.F. Santos, S. von Osmanski, Stability of rigid rotors supported by air foil bearings: Comparison of two fundamental approaches, Journal of Sound and Vibration, 381 (2016) 179191 doi:10.1016/j.jsv.2016.06.022

[6] J.S. Larsen, B.B. Nielsen, I.F. Santos, On the Numerical Simulation of Nonlinear Transient Behaviour of Compliant Air-Foil Bearings", SIRM 2015, Magdeburg, Deutschland, 2015, Paper-ID 39.

[7] J.S. Larsen, I.F. Santos, On the nonlinear steady-state response of rigid rotors supported by air foil bearings - Theory and experiments, Journal of Sound and Vibration, 346 (2015) 284-297 doi:10.1016/j.jsv.2015.02.017

[8] J.A. Walowit, J.N. Anno, J. N. Modern development of lubrication mechanics, Applied Science Publishers Ltd.: London (1975).

[9] H. Heshmat, J.A. Walowit, O. Pinkus, Analysis of gas-lubricated foil journal bearings, Journal of Tribology, 105(4) (1983) 647-655. doi: 10.1080/10402009208982082

[10] J-P. Peng, M. Carpino, Coulomb friction damping effects in elastically supported gas foil bearings, Tribology Transactions, 37(1) (1994) 91-98 doi: 10.1080/10402009408983270.

[11] I. Iordanoff, B.B. Said, A. Mezianne, A. Berthier, Effect of internal friction in the dynamic behavior of aerodynamic foil bearings, Tribology International, 41(5) (2008) 387-395.

[12] D. Kim, Parametric studies on static and dynamic performance of air foil bearings with different top foil geometries and bump stiffness distributions, Journal of Tribology, 129(2) (2007) 354-364 doi:10.1115/1.2540065 
[13] J.S. Larsen, A.C. Varela, I.F. Santos, Numerical and experimental investigation of bump foil mechanical behaviour, Tribology International, 74 (2014) 46-56

doi:10.1016/j.triboint.2014.02.004

[14] S. Le Lez, M. Arghir, J. Frêne, A dynamic model for dissipative structures used in bumptype foil bearings, Tribology Transactions, 52 (2009) 36-46 doi: 10.1080/10402000802065345.

[15] D.-H. Lee, Y.-C. Kim, K.-W Kim, The dynamic performance analysis of foil journal bearings considering coulomb friction: rotating unbalance response, Tribology Transactions, 52(2) (2009) 146-156 doi: 10.1080/10402000802192685.

[16] F. Xu, Z. Liu, G. Zhang, L., Hydrodynamic analysis of compliant foil bearings with modified top foil model, Proceedings of the ASME Turbo Expo 2011, ASME Paper No. GT $2011-46018$.

[17] M.F. Bin Hassan, P. Bonello, A new approach for modelling the foil structure in the simultaneous solution of foil-air bearing rotor dynamic problems, $11^{\text {th }}$ International Conference on Vibrations in Rotating Machinery (VIRM 11), September 2016, University of Manchester, IMechE, paper no. 1057.

[18] M. Petyt, Introduction to finite element vibration analysis, Cambridge University Press: England (1998).

[19] ANSYS Mechanical User's Guide. V15.0 User Documentation (2013).

[20] D.J. Ewins, Modal testing: theory and practice, Research Studies Press Ltd.: England (1995).

[21] C. DellaCorte, K.C. Radil, R.J. Bruckner, S.A. Howard, Design, fabrication, and performance of open source generation I and II compliant hydrodynamic gas foil bearings, Tribology Transactions, 51(3) (2008) 254-264. 
[22] L. San Andrés, T. H. Kim, K. Ryu, T.A. Chirathadam, K. Hagen, A. Martinez, B. Rice, N. Niedbalski, W. Hung, M. Johnson, Gas Bearing Technology for Oil-Free Microturbomachinery: Research Experience for Undergraduate (REU) Program at Texas A\&M University, Proceedings of the ASME Turbo Expo 2009: Power for Land, Sea, and Air (2009) 845-857, Paper No. GT2009-59920.

[23] R. Hoffmann, T. Pronobis, R. Liebich, A numerical performance analysis of a gas foil bearing including structural modifications by applying metal shims, SIRM 2015, Magdeburg, Deutschland, 2015, Paper-ID 49.

[24] D. Ruscitto, J. Mc Cormick, S. Gray, Hydrodynamic air lubricated compliant surface bearing for an automotive gas turbine engine I-journal bearing performance, NASA, Technical Report No. CR-135368 (1978).

[25] T. H. Kim, L. San Andres, Heavily loaded gas foil bearings: a model anchored to test data, Proceedings of the ASME Turbo Expo 2005, ASME Paper No. GT 2005-68486. 